\title{
STUDENT ATTITUDES TOWARD A NEW APPLICATION \\ OF INSTRUCTIONAL TELEVISION IN A \\ COMPUTER PROGRAMMING COURSE
}

\author{
By \\ THEROLD EUGENE BAILEY \\ Bachelor of Sclence \\ Harding College \\ Searcy, Arkansas \\ 1957 \\ Master of Sclence \\ Oklahoma State University \\ Stillwater, Ok lahoma \\ $\$ 962$
}

\footnotetext{
Submitted to the Faculty of the Graduate College of the Oklahoma Stace University

in partal fulfillment of the requirements

for the Degree of

DOCTOR OF EDUCATION

July, 1978
} 


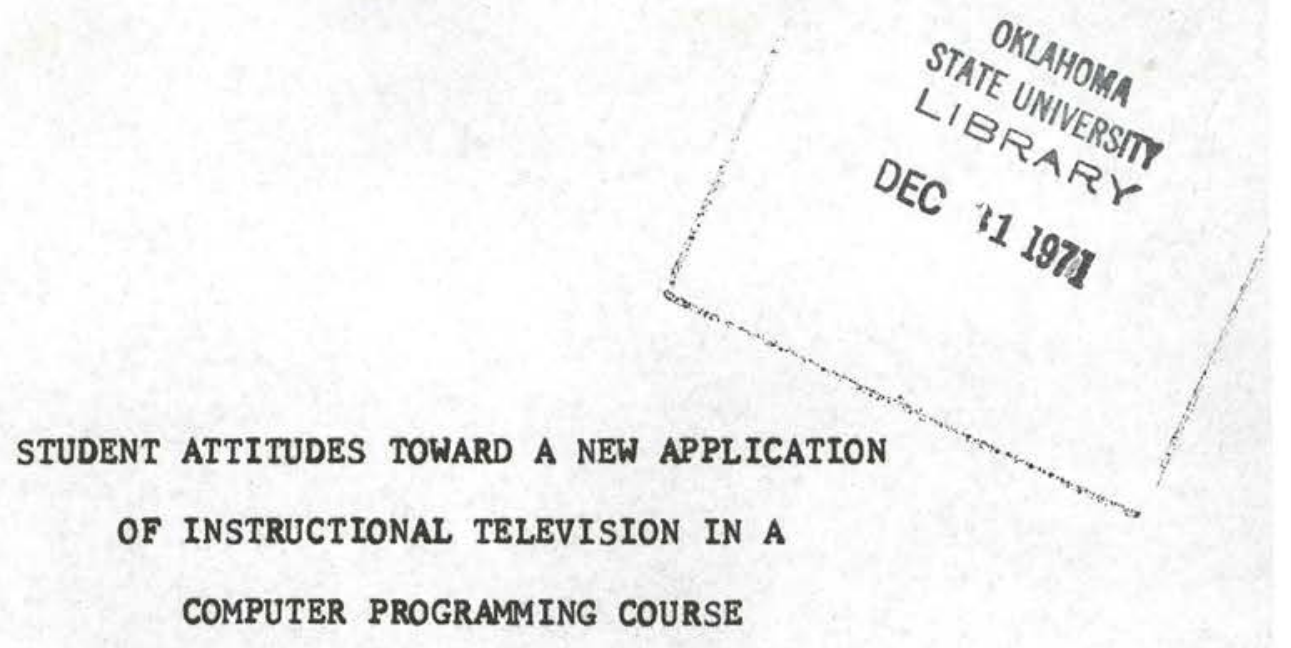

Thesis Approved:

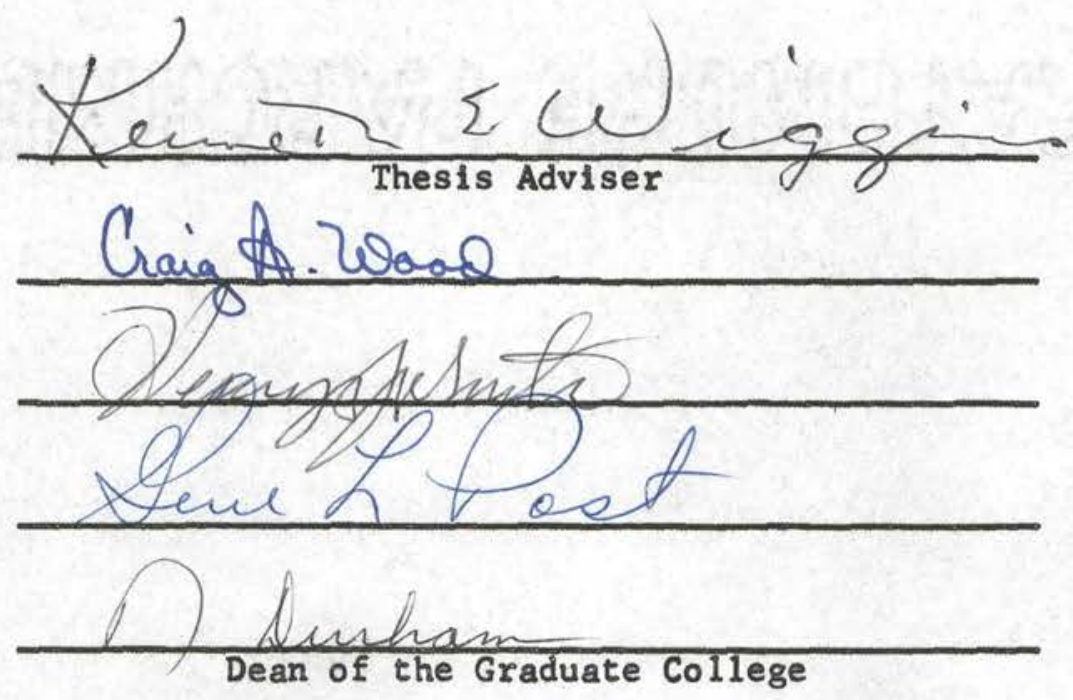




\section{Dedicated to}

HORACIO A. MOTTOLA

Who is sincerely committed to

The welfare of his students

And to

\section{KIM}

Who sacrificed some of her

Parents' time in my behalf 


\section{PREFACE}

When I was assigned the task of preparing a new instructional television series for a computer programing course, I really had no notion of what a challenging and rewarding experience the project would become. It required a fantastlc amount of work, a great deal of patience, and untold perseverance from all of the many people involved in the enterprise. Everyone cooperated splendidly, however, and the project was successfully completed approximately a year from the time of 1 ts beginning.

There are so many people to whom expressions of gratitude are in order. First I wish to thank Dr. Donald Fisher, Head of the Department of Computing and Information Sciences, who initiated the project and graclously allowed me to take over the task of developing 1t. He gave me his full support with helpful suggestlons and guidance, special commendations, and released time from my regular duties. I am also grateful for my assistantship provided by the Department during my graduate program.

Then I wish to thank the rest of the teaching team, Ellen Wood, and Carl Provence, who assisted directly in the preparation of materIals and in the making of the video tapes. I wish also to thank Pat Park, the departmental secretary, for the hundreds of pages of typing the she did so beautifully for the project.

Then there are the many people with the Oklahoma State University Educational Television Services (ETS). Ken Lane, the producer-director 
of the series, did a masterful job with the production. He had many helpful ideas for making the sertes better; he was also patient in recelving my ideas and procedural changes - even the last minute ones. There are others: Marshall Allen, Head of ETS, who gave words of encouragement and contributed Ideas; Frank Gibbons, formerly with ETS, who designed the set; Roger Bolton, Art Director, who designed and executed most of the visual materials; Charles Stacey, who prepared and managed the studio and did much of the photographic work; Wilbur Brakhage and Paul Smith, engineers, who worked patiently to make the equipment do what we needed and wanted; and Judy Vermelre, secretary, who relayed many messages and offered encouragement.

There are three people who contributed valuable ideas and assistance in the experimental study: Dr. William Rambo, Dr. Robert Means, and Dr. Larry Alexander.

My committee chalrman, Dr. Kenneth Wiggins, has helped me freely in the preparation of this thesis and in many other personal ways. H1s interest in me has been especially. significant in my entire graduate program. I wish to express appreciation to the rest of my comnittee, Dr. Craig Wood, Dr. Gene Post, and Dr. Henry Johnston, for their time and efforts in my behalf. The entire conmittee has been generous in their help.

The Untversity Computer Center also made a contribution in supplying a television camera and a typewriter terminal; B 111 Accola cooperated with me in scheduling the equipment. In addition, Iris McPherson of the Center ran the statistical analyses on the computer for me.

I wish to thank Donald Ely for his helping me with the analysis 
of the data.

I must also thank Dr. O. C. Dermer, Dr. Horacio Mottola, and Dr. Thomas Moore, all of the Department of Chemistry, for their consideration, understanding, friendship, and help throughout my graduate program.

I cannot omit the hundreds of students, and especially the stum dents in the experimental section, who have been through the new series and were asked several times for evaluations and comments. The splendid cooperation of the students in the experimental section is especlally appreciated. Bill Alexander helped me with administrative detalls of the experimental section.

Finally, I wish to thank Gwen and Ralph Jones - Gwen for typing this thesis for me, and Ralph for his loving friendship, support, and encouragement. 
TABLE OF CONTENTS

Chapter

Page

I. INTRODUCTION . . . . . . . . . . . . . . . . 1

Purpose and Scope of the Study . . . . . . . . . . 1

Background for the Study . . . . . . . . . . . 2

II. REVIEW OF THE LITERATURE . . . . . . . . . . . . . . . 7

Introduction . . . . . . . . . . . . . 7

Selected Studies . . . . . . . . . . . . . 8

Summary of Studies . . . . . . . . . . . . . 15

ITV in Transition . . . . . . . . . . . . . 15

The Future of ITV . . . . . . . . . . . . 19

III. THE NEW TV SERIES . . . . . . . . . . . . . . 21

IV. GIVING THE STUDENTS A CHOICE . . . . . . . . . . . 25

The Two Classes... . . . . . . . . . . . 25

Attendance Records for the Semester... . . . . . 28

Some Reasons for Attending as They Did . . . . . . 29

Some Interesting Inferences . . . . . . . . . . 33

V. TESTING SOME HYPOTHESES . . . . . . . . . . . . . 36

Some Assumptions . . . . . . . . . . . 36

Prior ITV Exposure . . . . . . . . . . . . . . 37

Types of Attenders . . . . . . . . . . . . . . 42

Changes in Class Attendance. . . . . . . . . . 48

Attitude and Performance ............ . 51

VI. SUMMARY AND CONCLUSIONS . . . . . . . . . . . 53

A SELECTED BIBLIOGRAPHY . . . . . . . . . . . . . . . . 55

APPENDIX A - OUTLINE OF THE TV LESSONS . . . . . . . . . . . 58

APPENDIX B - A SAMPLE SCRIPT FOR A TV LESSON . . . . . . . . . 65

APPENDIX C - QUESTIONNAIRE GIVEN AT THE BEGINNING

OF THE SEMESTER . . . . . . . . . . . . . . 85

APPENDIX D - QUESTIONNAIRE GIVEN AT THE END

OF THE SEMESTER . . . . . . . . . . . . . . 90 
$\begin{array}{ll}\text { Chapter } & \text { Page }\end{array}$

APPENDIX E - THE SCHULZE SHORT DOGMATISM SCALE . . . . . . . . 93

APPENDIX F - ATTENDANCE RECORDS FOR ALL STUDENTS

BY LESSONS . . . . . . . . . . . . . . 95

APPENDIX G - SUMMARY OF ATTENDANCE DATA BY STUDENTS . . . . . . 105

APPENDIX H - ATTITUDE SCORES, CUMULATIVE GRADE POINT

AVERAGES, AND PERFORMANCE IN THE COURSE . . . . . 108 


\section{LIST OF TABLES}

Table

Page

I. Some Results of a Questionnalre Sampling

Students' Responses Toward TV Instruction

in a Beginning Computer Programing Course . . . . . 5

II. Sumary of Attendance Data by Lesson . . . . . . . . 31

III. Summary of Attendance Data for the Semester . . . . . 31

IV. Summary of Reasons Given by Students for Attending Classes as They DId. . . . . . . . 34

V. Some Results of a General Questionnalre Given to

All Students Enrolled in the Course with the

Experimental Section Tallied Separately . . . . . . 35

VI. F-Table for Prior TV Exposure and Pretest

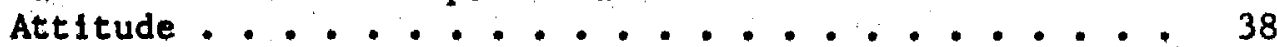

VII. F-Table for Prlor Exposure and Posttest Attitude .................. 39

VIII. F-Table for Prior Exposure and Course Performance .................. 40

IX. F-Table for Prior IV Exposure and Absenteelsm . . . . . 41

$X$. F-Table for Prior TV Exposure and Change in Attitude From Pretest to Posttest . . . . . . . . 42

XI. Type of Attender and Pretest Att1tude . . . . . . . 43

XII. Type of Attender and Posttest Attitude . . . . . . 44

XIII. Type of Attender and Change in Attitude

From Pretest to Posttest . . . . . . . . 45

XIV. Type of Attender and Course Performance . . . . . . . 46

XV. Type of Attender and Absenteeism . . . . . . . . 46

XVI. Type of Attender and Dogmatism . . . . . . . . 47 
XVII. Type of attender and GPA ............... 48

XVIII. Correlation Matrix ............... 49

XIX. Attendance Records for All Students by Lessons . . . . 97

XX. Summary of Attendance Data by Students . . . . . . 106

XXI. Attitudes, Cumulative Grade Point Averages, and Course Performance ............. 110 


\section{IIST OF FIGURES}

\section{Figure}

Page

1. Graph of Attendance After Students Were Free to Choose the Class They Wished to Attend 


\section{CHAPTER I}

\section{INTRODUCTION}

Purpose and scope of the Study

In general, students exhibit a rather negative attitude toward the use of Instructional television at the college level. One reason for this is that the real potential of television as a teaching medium has rarely been explolted. Many applications of television in the classroom have been framed in the same format that is used in the traditional lecture, and only the ability of television to transport and multiply the visage and volce of the instructor is utilized.

Will ams (43) has suggested that it seems reasonable to suppose that an instructional television series that is designed around the special capabilities of television should be able to do a better fob of teaching certain types of material than the conventional lecture method. Student attitudes toward television should be at least relatively good if television teaching is interesting and informative and wastes as little as possible of the students' time.

The purpose of this study is to demonstrate that an instructional television series, designed with careful consideration of what television is and is not able to do, can eliclt a favorable response from students.

The scope of the study is 11mited to the production of a new television series for a computer programing course and a measure of 
students' attitudes toward the series.

$$
\text { Background for the Study }
$$

For approximately three years during the period of 1967 to 1970 the beginning computer programing course (Computer Science 2112) at the Oklahoma State University was taught using instructional television (ITV). The course was structured with a television lesson once a week and a two-hour laboratory once a week. The television lessons were done in a conventional lecture format.

Student response to the television series was quite negative as evidenced by a high rate of absenteeism, a high percentage of sleepers among those who did attend, and constant complaining on the part of the students that the IV class was a waste of time. Results of a questionnaire that was given at the end of the last semester in which the IV series was used (Spring Semester, 1970) indicated something of the negative attitude of the students. Only $85 \%$ of the respondents said that they attended the TV class with any regularity. Only $35 \%$ of the respondents indicated that they thought that the TV lessons were informative, whlle a smal1 $11 \%$ felt that the TV lessons were interesting. Respondents indicated by $12 \%$ that they preferred a TV class to a "live" class.

The old TV serles clearly had serlous shortcomings that made its use as a teaching medium of questionable value. As plans for the future use of instructional television in the course were being considered, certain basic questions had to be answered. Can television instruction be used for teaching computer programing? Is it possible to design a television series in computer programming that will be 
both informative and interesting? What must be done in order to produce such a television series, if indeed one can be produced?

In answer to the first question, a long period of deliberation turned up no particular reason why television instruction could not be uspd for teaching computer programing. A significant reason for using instructional television was the large enrollment in the course and the use of graduate assistants as instructors. By using television instruction for presenting the basic material in the course and then letting graduate assistants develop the material given in the TV lessons, the course could be fairly well standardized for all the students. In addition, television could be used quite effectively for showing closeups of computer cards and output and for showing computer equipment in operation to large numbers of students.

The answer to the second question was more difficult. What criterla should be used in characterizing the words informative and interesting? As a working description of informative, it was decided that an informative presentation should be characterized at least by a clear, concise, well organized presentation that is easy to follow and to understand. A presentation that is interesting should be characacterized at least as grasping the student's attention and holding it throughout the lesson and motivating the student to learn material that is challenging, but st 11 comfortable. A preliminary investigation of possible ways of achieving the objectives of interesting and informative seemed to indicate an affirmative answer to the basic question under consideration; there are ways of making an instructional television series both informative and interesting. 
The third question was, of course, the most difficult of all to answer. The details of exactly how to produce a series that would achleve the objectives were rather elusive, but intuition coupled with trial and error did in fact reveal a workable solution. A detailed description of methods used to achieve the objectives is given in Chapter III.

A new television series was produced and taped during the first eight months of 1970 and was used experimentally during the Summer Session of 1970. The response of the students was greatly encouraging. The same questionnaire that was given to the students taking the old series during the previous Spring Semester was given at the end of the Summer Session. In sharp contrast to the results of the previous group, $98 \%$ of the summer group indicated that they attended the TV class with regularity. An exciting $90 \%$ of the respondents indicated that they thought that the TV lessons were informative, while $83 \%$ felt that the TV lessons were interesting. Perhaps most surprising was the 48\% that indicated a preference for a IV class over a "live" class. These preliminary results indicated that the objectives were being fulfilled to an encouraging degree. Revisions were made in the series in order to improve the quality and to remove glaring errors in both the material and the presentation. The series in its final form was then used during the Fall Semester of 1970 .

Again the same questionnaire was given to the students at the end of the Fall semester. The results, while not so strongly positive as those of the Sumer Session, were very encouraging. of those responding, $92 \%$ sald that they attended the TV class with regularity, and 61\% of the respondents indicated that they thought that the TV lessons 
were informative, while $41 \%$ felt that the TV lessons were interesting. Indicating a preference for a TV class over a "live" class were $32 \%$ of the respondents.

The results of the questionnalre for the three groups cited are summarized in Table I.

TABLE I

SOME RESULTS OF A QUESTIONNAIRE SAMPLING STUDENTS'

RESPONSES TOWARD TV INSTRUCTION IN A BEGINNING

COMPUTER PROGRAMMING COURSE

\begin{tabular}{l|c|c|c}
\hline & $\begin{array}{c}\text { Old TV } \\
\text { Series }\end{array}$ & \multicolumn{2}{|c}{$\begin{array}{c}\text { New TV } \\
\text { Series }\end{array}$} \\
\cline { 2 - 4 } & Spring 70 & Summer 70 & Fall 70 \\
\hline Attended class regularly & $85 \%$ & $98 \%$ & $92 \%$ \\
Thought TV lessons were informative & $35 \%$ & $90 \%$ & $61 \%$ \\
$\begin{array}{l}\text { Thought TV lessons were interesting } \\
\text { Expressed preference for TV class } \\
\text { over conventional class }\end{array}$ & $11 \%$ & $83 \%$ & $41 \%$ \\
\hline
\end{tabular}

Since the preliminary results of using the new IV series with two groups suggested that the original objectives of producing informative and interesting IV lessons were being achieved to an encouraging degree, a formal study was undertaken during the Spring Semester of 1971 in order to determine whether student attitudes were favorable toward the IV series. The experimental procedure, the experimental group, and the data collected during the semester are discussed in Chapter IV. Several hypotheses, relating prior exposure to instructional television, 
and attitude as measured by attendance data, to some attitudinal and performance variables, are tested and discussed in Chapter $V$, along with some hypotheses correlating certain attitudinal and performance variables. Conclusions that may be drawn from the study and Implications regarding the future of instructional television at the college level are discussed in Chapter VI. 
CHAPTER II

\section{REV IEW OF THE LITERATURE}

\section{Int roduction}

In the early 1950's when commercial television was beginning to take hold across the nation, the possibilities of the use of television in the educative process began to be explored and implemented. The educational television (ETV) stations began to make their appearance. This venture was launched with practically no money behind it - a condition that too often has prevalled throughout the entire experiment. The closed-circuit television (CCTV) systems sprang up on some university campuses, and television teaching "in house" was begun. Some educators, pressed by the great surge in enrollment in higher education, increasing costs of education, and the shortage of teachers, accepted the notion that instructional television (ITV) would alleviate the difficulties faced by institutions of higher learning. The CCTV systems faced the same basic problem of the educational television stations, however, being for the most part poorly funded and inadequately staffed. Gllkey (8) cltes the lack of money as a major reason for the fallure of television to meet the needs of education.

The next decade ushered in at 1 ts beginning and out at its end the great educational experiment with television. Numerous studies were intiated in the utilization of television for teaching a variety 
of subjects to a varlety of students from preschool children through adults. For the most part, these experiments used the conventional classroom lecture transmitted through the medium of television; this fact is of great importance in evaluating the impact of television teaching - a fact whose implications are generally overlooked. There were other uses, however, besides the televised lecture, most notable of whlch was the use of television in demonstrations such as one might find in science classes.

of necessity the scope of this review must be 1 imited primarily to the use of television at the college and university level. A further restriction is imposed by the exclusion of public broadcast television. In many areas, however, public television and instruce tional television overlap. The primary concern of this review is to summarize the two decades of instructional television of the closedcircuit type employed at the college and university level.

\section{Selected studies}

The studies that have been reported in the use of CCTV for instructional purposes constitute a vast amount of literature. There are at least two notable review articles summarizing much of the literature; these are by MeKeachie (22) and by Chu and Schramm (5).

The review by MeKeachie was published in 1963. Special attention is given to the use of instructional television at Pennsylvania state University, New York University, and Mlami University. A number of varlables were Investigated, such as class size, the use of visual materials, student achlevement, student attentiveness, student attitudes, student ability, faculty attitudes, and subject matter taught。 
Some conclusions that were drawn from these studies follow: Class size bears no relationship to learning; use of visual materials seemed to be less effective than a "straight" televised lecture; achievement of students seemed as good as those taught by conventional methods; students paid ilttle attention to the television monitors, Indicating that most of the learning took place through audlo stimuli or through some other source; students were generally negative toward television teaching; student ability and student evaluation of ITV were inversely related; att tude of faculties was generally negative; levels of achievement and attitudes of students seemed unrelated to subject matter. The most general conclusion that can be drawn from these studieg is that there is "no significant difference" between the learning of students by conventional teaching methods and by Instructional television, even though attitudes were generally negative. MeKeachie stated his conclusion this way:

Taking the results of all research on television instruction, we feel safe in concluding that television instruction for a complete course is inferior to classroom lectures in commun cating information, developing eritical thinking, changing attitudes, and arousing interest in a subject, but that this inferlority is probably not great . . . When one welghs heavily the necessity for accommodating higher education to large numbers of students, however, the differences between television and conventional instruction seem very small.

McKeachie footnotes one additional comment of great importance:

Note that most research has dealt with television as a substitute for conventional instruction. The potential of teleo vision as tool for enriching classroom teaching has not been assessed.

The review by Chu and Schram (5) is rather more favorable in its evaluation of instructional television. The authors, unlike Mckeachie, 
review the full gamut of instructional television ut lization. of particular importance is the finding that there was an inverse relationship between the level of schooling and favorable attitudes toward instructional television. Lack of two oway communication (feedback) Is cited as one possible explanation for this, but they conclude that lack of feedback does not necessarily seem to handicap learning. As the material becomes more complicated, however, inablity to question the teacher may become significant in reduclng the effectiveness of learning from instructional televiston. The authors discuss the application of a technique found useful in programmed instruction, testing and revising televiston lessons in order to overcome to some extent the problem of lack of feedback. The taking of notes may Interfere with learning from television instruction, if the telelessons are improperly structured. Some of the conclusions of Chu and Schramm are summarized in the following quotations:

For one thing, it has become clear that there is no longer any reason to raise the question whether instructional television can serve as an efficlent tool of learning. This is not to say that it always does. But the evidence is now overwhelming that it $\mathrm{can}_{\text {, }}$ and, under favorable circumstances, does. This evidence now comes from many countires, from studies of all age levels from preschool to adults, and from a great varfety of subject matter and learning objectives. The questions worth asking are no longer whether students learn from $16_{2}$ but rather, (1) does the sltuation call for it? and (2) how, in the given situation, can it be used effectively?

Beyond those larger considerations, the research seems to suggest that effective use of television grows out of attention to the basic requirements of good teaching, rather than to any fanciness that might be, peculiar to television. The quilities that emerge from the research described. o are qualities like simpliclty, good or ganizatlon, motivation, practice, knowledge of results, rest pauses at appropriate points, cues that direct the pupil to the essential things he is to learn.... 
Teaching on television can be as interesting or as unin. teresting as most classroom teaching; and we ought to know enough now about the quallties of good teaching, and have enough experlence with bringing resources to bear on prew paring good television classes, to reduce the proportion - of uninteresting teaching to a minimum。

Chu and Schram, like McKeachie, point out an Important key to understanding the overall lack of success of instructional television.

There are sufficient number of favorable reactlons in the higher academic levels, and a sufficlent number of unfavo able ones in the lower grades, to lead us to suspect that the way television is used, ather than the grade level, controls the attitude.

In this same line of thinking, Guba and Snydex (13), in a detalled study involving utilization of instructional television in elementary schools, point out that the chief shortcoming of television in the classroom is the unimaginative "gray curtain" effect of instructional television; the real capabilities that televiston has to offer are rarely used.

A detalled study of CCTV used in teaching an introductory bus 1ness course at Indlana state University is reported by Herrington and Knoblett (14), The authors concluded that "students in the experiment.al group generally achieve at a lower level than predicted and lower than comparable students in the control group." It is important to take note of the fact that the television lessons consisted of simply televising a classroomatype lecture.

Rawls and Rawls (32) report a study in the use of CCTV for teaching educational psychology at Louisiana State University. They summarized their findings as follows:

Results indicated that the were no significant differences in achlevement and retention of students taught by conventional and televised instruction. Students in general beld highly unfavorable attitudes about television instruction 
and strongly preferred the conventional classroom approach. - Students paid little heed to the image on the screen and were observed looking in the direction of a television set only $20 \%$ of the time; students in conventional classes looked at the lecturer $42 \%$ of the time.

As in the previous study cited, the television instruction consisted merely of a televised classroomotype lecture. In this regard, the authors point out that

it appears on the surface that televised instruction might be readily replaced by the tape recorder. An obvious alter. native explanation, of course, is that the visual medium was not used to full advantage.

Some suggestions for improving the course and criticisms of the course are reported. Graduate students assisting in the television classes reacted as follows:

(1) Utilize more visual aids, demonstrations, attention getting devices, etco

(2) Make use of outside speakers and guest lecturers.

(3) Provide more camera positions.

(4) Have lecturers watch themselves on the monitors.

Students in the television classes reacted as follows:

(1) More visual aids and demonstrations are needed.

(2) Guest lecturers and outside speakers should be provided。

(3) More communication with lecturers is needed.

(4) There should be more explanation and discussion of televised lectures.

(5) More inflection and range of volces are needed.

(6) The lectures are too impersonal.

The authors conclude their artsele with these words:

Certainly 。. televised instruction should not be used to espouse or $1 \mathrm{mplement}$ conventional instruction but to provide instruction which conventional methods cannot.

Moss (26) reports on the use of instructional television in the teaching of English literature, both on public television as well as on CCTV. He records some student reactions to the CCTV used in the classroom. 
You might as well mimeograph these lectures and have us read them . . . Television has fantastic potential for enriching a lesson - photography, sound effects, music, characterization, prints, etc. Why ... didn't they use them? One important thing [is lacking] - imagination.

Some suggestions for improving the television lessons were

1. More audiovisual aids.

2. Use of costumes, sets, etc.

3. Professional readers.

4. Color.

5. Better camera work (more Imaginative)

Moss makes these crutial observations regarding the utili-

$z$ ation of the full potential of instructional television:

The challenge lies in employing more creatively that medium's unique capabilities - not to be content, that is, merely with a taped recording of conventional "background" facts or undeveloped themes. The loss of the classroom's immediacy must be compensated for by more than an occastonal use of slides or other simple audiovisual techniques.

The televised offerings must be carefully designed to penetrate the coldness of the picture tube and the passivity of the viewing audience.

The goal of instructional television should be to guide thought, not to circulate information or undeveloped generalities.

Several studies have been done which investigate students"

attitudes and responses toward ITV. Becker,(2) found, using galvanic skin response, push-button response, and pencil response, that the Interest in the IV lesson indicated by the student had little to do with how well the student learned.

We conclude that whether the student in the classroom finds what he is viewing interesting or tension arousing has little to do with the new knowledge he wlll galn from that viewing.

Janes (17) investigated response to the use of ITV in terms of preexisting attitudes which the students brought into the classroom authorltarianism, selfoconfidence, and intelligence scores. 
The results of the study suggest that none of these particular qualities. . . operate to inhibit student learning predicted on televised instruction.

A11 measures showed a positive statistical correlation with preference for televised lectures.

- - The evidence does indicate that a course which presents the subject matter to beginning undergraduates can be organized effectively around a televised presentation. None of the preexisting student attitudes and capacities examined in this study provide predispositions which limit most students from developing positive reaction to lectures by television.

Rayder and Neldt (33) found that attitudes toward IV declined during the semester. In particular they studied the effect of the frequency of attitude testing on the attitude measured and found that the decline in attitude was not "necessarily a function of repeated measurements during the learning experience."

Use of ITV in programmed instruction has been investigated. Gryde (12) explored the possibilities and found that ITV lacks only three of the criteria used in programmed instruction: feedback, pacing, and active response. He gives suggestions for overcoming these inadequacies.

Perhaps a more significant application of the techniques of programmed instruction is in preparation of televised lessons. An instructional presentation can be videotaped, used and tested, then revised in order to remove inadequacies. In this way a lesson can be "tuned" to a high level of efficlency, just as material for conventional programed instruction is prepared. Gropper (10) discusses this technique in detail.

A number of special uses of ITV have emerged. Most of these make use of portable videotape recorders that are avallable now at 
relatively low cost. Applications of ITV in teaching chemistry for demonstrations both in the laboratory and the lecture room are dis. cussed by several authors $(1,16,28)$. Use of ITV in classes in which students perform is discussed by Gross (11). Closely related is the application of ITV in the training of teachers $(7,20,21)$. Neidt (27) reports the use of videotapes in teaching study skills to beginning students.

Summary of Stidies

What conclusions can be drawn from these reports and studies? Students have been able to learn in spite of the use of television instruction, but they generally do not like television classes. Administrators, st111 thinking in terms of the efficacies of television for some of the 111 s of higher education, have been rather favorable toward the introduction of instructional television, while faculty members too often took the presence of the television monitor In the classroom as a threat to themselves and their autonomy. In general, television utilization has been relegated to the role of the traditional lecturer, and the real capabilities offered in unique ways by television have not been used, although the trend is now away from the traditional approach.

Television cannot fulfill the role of the traditional classroom lecturer, nor can it replace the teacher.

I $\vec{T} V$ in Transition

The fallure of instructional television to fulfill the expectations of the early $1950^{\prime}$ 's has produced a great deal of effort to 
understand its fallure. Results of studies and experiences in the use of ITV have pin-pointed the weaknesses and the misuses of the medium. Gilkey (8) summarized the situation well when he suggested that the greatest weakness of ITV is the use of illustrated lectures, panel discussions, and related undynamic formats. Furthermore, "while lectures were bad Iive, they were even worse when recorded on videotape or transmitted via television." Slepmann (38) was even more pointed.

That such a primer [on the use of instructional television] is needed comes clear when you note how frequently newcomers to ITV repeat the past errors... of their ploneer forerunners. The result is doubly disastrous. The television medium is misused, and outworn practices in education (by harnessing television to them) are given the veneer of a spurious modernity.

In short, the full potential of television has rarely ever been explofted or even approached. Teachers were often reluctant to succumb to the televised classroom; and when they did, the conventional lecture method was simply piped into monitors with little or no thought given to the medium itseif as a vehicle for teaching. Equipment was usually of inferior qualty and was generally manned by amateur personnel. The result was simply a poor teaching and learning situation unimaginative, uncreative, and uninteresting.

Instructional television and its utilization are now in a transio tional period. The use of television for televised teaching is being replaced by a more suitable concept of television teaching, that is, telelessons that are designed around the capabilities of television and what it can do that cannot be done otherwise. Wolfe (44) summ marizes this new approach as follows: "Use television only when its proper application will improve learning.... Design every session specifically for this medium." Siepmann (38) lays the ground rules 
in these words: "The golden rule of ITV is never to use it except where it fills a vacuum of need, and always to use it professionally. Avold amateurism like the plague."

A number of other authors have written on the subject of how to make use of ITV in creative and innovative ways $(4,29,39,40)$. Meyer (24) sumnarizes some important problems that must be dealt with in order to improve the quality of ITV.

Aside from the present stumbling blocks to TV in higher education, which include faculty and administration resistance, lack of money, and the traditional college lecture approach to programming, the grossest omission is in the area of research and development. It is true that research and development have occurred in the area of engineering and hardware, but almost no instructor of higher education in the United States is experimenting with the software or programing aspects of the medium. Instead, TV programs and college credit and noncredit courses are being produced meat ogrinder fashion through the U. So These appear on closed-circuit as well as open-circuit TV. The entire area of pure research into the nature of the TV medium and its applications to varlous problems of higher education remains untapped. Instead of reviewing these undertakings, most of which are mediocre, this writer will suggest a way in which research and development can take place in IV for higher education.

Those engaged in the profession of higher education must capture the TV medium rather than apathetically "view" the present condition in which TV enslaves their world. $A$ kind of Bauhaus located on or near the campus of a university must be created to be part of an on ogoing process in the development of the TV medium for education...

- . This writer strongly urges that those engaged in the profession of higher education immediately wrest the TV medium from the entrepreneurs, turn the medium into air waves that will purify the urban environment, and begin to experiment in the nature of TV and apply the discoveries to the myrlad problems which exist in our soclety.

Evidence clearly indicates that just any teacher will not necessarily be a good television teacher. Montgomery (25) cites the survey by Hoffman of the Great Plains Instructional Television Library and 
1ists some of the criteria that ITV administrators surveyed felt were important in choosing a television teacher. The ones listed and discussed are ability to communicate by television, having a command of the language, being a content specialist in the area to be taught, general maturity, ability to organize materials, ability to work under pressure, imagination, showing a desire to function in the medium, ability to get along with people, personality, general cultural background, showmanship, and teaching experience, Blenheim (3) even explored the use of professional television people for teachers or communicaters on television, but experienced teachers performed with better results than did the professionals. (His study made use of the television lecture, however.)

Television has certain limitations, of course, as does any medium for teaching. Television teachers must realize just exactly what can and cannot be done with television. Siepmann (38) says that "ITV is not a panacea, an alibi for teaching, a substitute for teachers, or just one thing with one use or purpose."

There are a number of things that television can do, and many of these are unlque. Siepmann (38) lists three: "ITV can put teacherartists into every classroom, rescue schools where there is no teacher for particular subjects, and make use of team teaching." Special capabilities of television are elaborated more fully by Wolfe (44) and Tyler (41): magnification, multiplication (feeding the signal to any number of monitors), transportation (bringing the teacher or teaching situation to the learner, rather than requiring that the learner be brought to the teacher), association (using special effects, such as matting, split screen, and supers), framing 
(centering on particular objects, words, or concepts being emphasized), contrast (highlighting important polnts visually), recording of rare incidents (particularly useful in medicine), personalization (eyeto-eye tutorial approach), and sharpening performance by selfevaluation of video tapes. This list is a very good summary of techniques for utilization of television for effective teaching. According to Gilkey (8),

Developments in technology and experlence with past television programing [are] structuring an [entirely] new approach to television in elementary schools, high schools, and universities. Most significant is that the use of television as a means of transmitting or permanently recording an illustrated lecture is on the way out. This is no longer a signtficant use of television.

The Future of IIV

Writers in the current 11terature seem convinced that television is here to stay. The transitional period from the televised lecture to television teaching is apparently progressing well. The trend seems to be in the direction of Imaglnative and novel applications (not novel just for the sake of novelty, however) of instructional television.

A number of authors are suggesting that instructional television definitely has a place in a total systems approach to education $(9,29$, 38). Gill (9) lists some particular advantages of television in such an approach: trying out new techniques of teaching; supplying inquiry materials that do not give answers; providing overviews of materials, leaving the detalls to the learner; testing; and demonstrating concepts. 
The future of instructional television not only seems assured, but also, much more happlly, Indicates great promise. It must be remembered, however, that the hopes of twenty years ago were not adequately fulfilled by utilization within the traditional framework of education. Only a dynamic and creative approach to the use of instructional television will prevent the dashing of present renewed hopes for the future.

Slepmann (38) suggested the greatest single problem of the passIng era of instructional television: "G. K. Chesterton once said that the trouble with Christianity is that it has never been tried. Much the same could be sald of ITV - or, for that matter, of real, lifegiving education." Such a remark hopefully cannot be said of the new era of instructional television. 


\section{CHAPTER III}

\section{THE NEW TV SERIES}

An operational description of what should characterize the new television series was introduced in Chapter I. The basic objectives were to produce a television series that is both informative and interesting.

In order to be informative the television lessons must present the material in a well organized, meaningful, clear, and concise manner. The following procedures were used in accomplishing this general objective.

In order to enhance the teaching of problem solving using the tools of the FORTRAN language and a computer, the problems in the television lessons were designed to be simple, yet relatively comprehensive; problems that could be easily visualized by actually physically performing the solution or problems that could easily be encountered in dally affairs were chosen. Each lesson was bullt around the solution of one particular problem.

New statements and capabilities of the FORTRAN language were introduced within the framework of the problem being solved as they were needed. In this way new material was not introduced just for its own sake, but rather was introduced as the need for it arose in the solution of the problem under consideration.

The material of the course was organized so that all of the 
fundamental material was introduced by the end of the sixth lesson. The remaining seven lessons introduced more sophisticated concepts of computer programing, at the same time reviewing all of the fundamental material and using it at a deeper level. This additional reinforcement was used for increasing the probability that the students would be able to grasp the material and also for demonstrating the uses of the programing language in a wide vartety of contexts.

An effort was made to organize the material of the course so that the students could be led logically and naturally from simple concepts to more complex ones with a minimum of difficulty.

Excessive detail was omitted from the lessons and a general overview of each lesson was emphasized.

A set of written materials was prepared to accompany the lessons, summarizing the lessons and explaining potentially difficult material. Using these materials, the students could have a review of each lesson at thetr conventence.

An effort was made to anticipate questions that would arise in the students' minds as the lessons progressed and to deal with these questions in the lessons.

In order to be interesting the television lessons must gain and maintain close attention to the material being presented. The followIng procedures seemed especially appropriate for accomplishing this general objective.

The lessons were usually restricted to approximately thirty minutes (or less) in length. 
The material in the lessons was presented in a series of "rapldfire volleys," having been organlzed in short segments; and new materlal was presented falrly rapidly, followed usually by some form of restatement in a later segment of the lesson.

A team of three television instructors was used with at least two of them appearing in each lesson (with the exception of one lesson). The organizing of the material into short segments was enhanced by the changing of instructors with the beginning of each segment.

A female instructor was included in the teaching team in order to accent the use of different teachers and volces.

An off-camera volce was used in the lessons for stating and/or reinforcing important principles and for teaching certain aspects of the syntax and form of the programming language. (These potentially less interesting parts of the course were generally introduced only by use of the off-camera volce and visual materials. These blurbs were designed to be very short and attention demanding.)

The lessons were oriented heavily toward visual materials. The "face on the screen" was avolded as much as posstble.

The lessons were prepared in a conversational format rather than a stralght lecture format.

The set of written materials prepared to accompany the lessons minimizes the need of students to have their attention distracted by note taking.

A typewriter terminal connected to a computer was placed in the set and was used so that students could see the written output from the computer as it was being produced. 
Use of special effects (split screen, matting, spotlighting, etc.) was employed as much as possible.

Not all of the "answers" were given in the lessons. Some of the material was deliberately left unsald in order to stimulate the students to question and hopefully to find some answers for themselves. Some "previews" of material to be covered in later lessons were inserted at strategic places in the lessons so that the students might be encouraged to anticipate material that would be covered later.

No evidence was found in the literature of a college level course having been couched in a format like that described above.

An outline of the material presented in the TV lessons is given In Appendix A, and a sample script for a TV lesson is given in Appendix B. 
CHAPTER IV

\section{GIVING THE STUDENTS A CHOICE}

\section{The Two Classes}

Measuring attitudes is, of course, a difficult task. Since questionnalres and opintonnalres have limited crediblity, some behavioral measure of attltude is probably more rellable.

Based upon the assumption that a student will, given two alternatives, choose the one that appears to him to be more suitable for his purposes, a plan was devised whereby a student could choose between a television class and a conventional class covering the same material. Two sections of students enrolled in the course were selected and combined Into one section, since both of these sections were scheduled to meet at the same time. The two rooms which were scheduled for the two sections are 1dentical to each other and are on the same floor of the same bullding; both are set up for TV viewing rooms. One of the rooms was designated as the place to 80 if the student wished to view the tefevision lesson, while the other room was set aside for a conventional class should the student choose to attend that class. All students were given an open-ended cholce during the semester of attending the the IV elass or attending the conventional class or not attending at a11. They were allowed to change from one class to the other as often as they wished, but they were expected to remain for the entire class 
period once they had made the cholce for that particular day. The instructor chosen for the conventional class was the main television instructor of the TV series, while the person in charge of the television class was one of the assistant instructors in the TV series. Thus each class had the "prestigue" of having a television instructor in the classroom. The instructor giving the conventional presentation was the one who had written most of the material for the IV series; it was assumed that he would best be able to duplicate the material in the TV lessons for presentation in the conventional class.

In at least two senses the conventional class was not entirely conventional. The organization of the material in the special way that was used in the TV lessons made the conventlonal class more structured and more rigidly paced than would probably be expected in the usual conventional class. All students had access to the printed materials that are an essential part of the television series, and these printed materials were used in the conventional class because they were available and because their use was necessary in order to conserve time that would ordinarily be wasted in writing on the chalkboard. (Actually more materlal was covered in the TV lessons than could be covered in a conventional class period. One of the advantages of TV instruction is the elimination of most of those things that take up time in the classroom, but probably contribute little or nothing to the student's learning. Even with the printed materials that were designed to accompany the TV lessons the instructor was hard pressed to cover in a fifty-minute period the same material that was covered in a thirtyminute TV lesson.) The conventional class was conventional mainly in that it had a "live" lecturer with whom the students could interact 
during the class if they wished to do so by asking questions or requesting further explanation.

The first class meeting of the semester was devoted to an ortentation pertod for the combined sections in a single room given "live" by the instructor who would be conducting the conventional class. An explanation of the two classes and the students' freedom to choose during the semester was given. The students were told that their cholces would in no way be linked directly to their grades in the course, since no grades are kept by lecture sections in the course anyway. (A11 grading is done in the laboratory sections.) Each student was given a packet of computer cards which would serve as his "tickets" to either class during the semester. There was a card for each lesson with the date, the lesson number, the student's name, and some other information for record keeping purposes punched in the card. The student was to present a card for the particular date at the door of the classroom so that exact attendance records could be kept for each student during the entire semester. The use of punched cards made the processing of the data with a computer a relatively simple matter.

During the first class meeting all students were given a questionnalre which provided background information on each student for later use. of particular interest was the student's prior exposure to instructional television at the elementary, secondary, or college level. In addition, a sampling of the student's attitude toward the use of instructional television in general and in this particular course was obtained, along with what he expected his attitude toward instructional television to be at the conclusion of the course. This questionnaire is shown in Appendix $C$. 
In order to introduce those students who had never attended a class using television instruction to at least one IV lesson, all students were required to attend the first IV class. (There was a very practical reason for this requirement too. Some of the special capabilities of television had been employed to a large extent in the first lesson, and much of the material in the lesson could not be presented easily without the use of television.) For all subsequent classes, however, students were free to choose the television or the conventional class.

The experimental section finally contained eighty-one students after drops (including one student who was auditing the course). There were a few more students enrolled, but they enrolled late and did not take the pretest questionnaire and did not attend the orlentation session; so they were not considered to be experimental subjects.

At the conclusion of the course another questionnaire was administered which asked some of the same questions that were asked on the first questionnaire. At the same time the Short Dogmatism Scale of Schulze (37), which is a shortened form of the Rokeach Dogmatism Scale (36), was given in order to determine, if possible, whether any relatlonship existed between dogmatism and the acceptance of instructional television. A copy of the questionnalre is shown in Appendix D, and a copy of the dogmatism scale that was used is given in Appendix E.

Attendance Recards for the Semester

When the students exercised their cholce for the first time, the majority of them chose the conventional class. When the second cholce 
was made a majority chose to attend the TV class. More of the students chose the IV class for the remainder of the semester than chose the conventional class.

A graph of the attendance for the semester after the students were free to choose (beginning with the second lesson) is shown in Figure 1. The graph suggests that most of the students had fairly well decided upon a class to attend early in the semester. (The large number of absentees for the fifth lesson occurred because of a blizzard on 2122 February. A number of the students who were absent viewed the lesson later on a video tape machine in the Library. What effect, if any, this "forced" viewing had on later attendance is, of course, unknown.)

The attendance data by lessons for all students are included in Appendix F. A summary of the attendance by lessons is shown in Table II. (The graph in Figure 1 was prepared from this table.) A summary of the attendance data during the semester is shown in Table III, and the data from which this summary was derived are given in Appendix $G$.

Some Reasons for Attending as "They Did

In the last questionnaire that was given to the students, they were asked to write their main reasons for attending (or not attending) classes as they-did. Only $91 \%$ of the students could be reached and given the questionnaire; and not all of the students who took the questionnalre responded to that part, but for those $77 \%$ of the students who took the questionnaire and responded, several reasons seemed to stand out for attending the TV class or for attending the conventional class. 


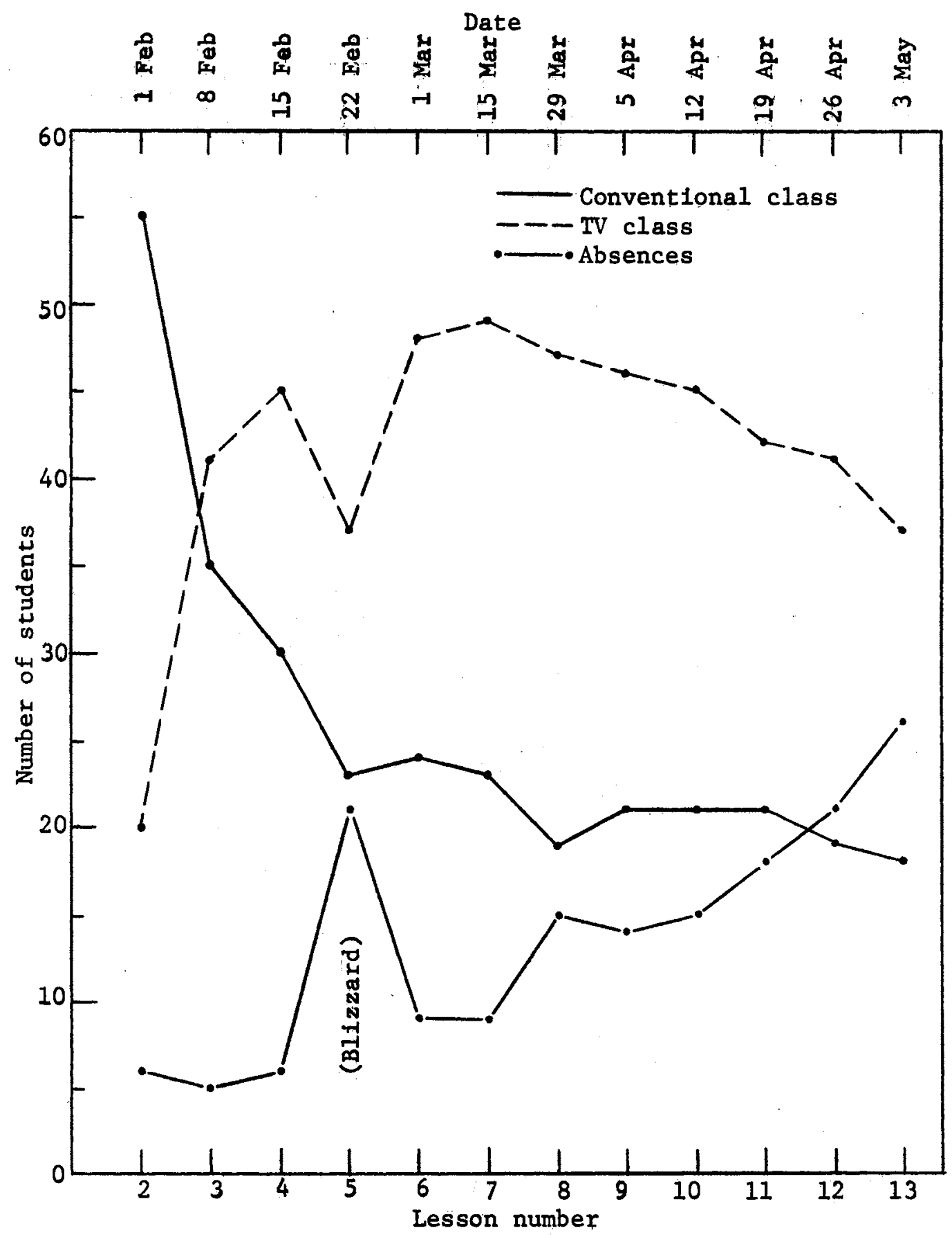

Figure 1. Graph of Attendance After Students Were Free to Choose the Class They Wished to Attend 
TABLE II

SUMMARY OF ATTENDANCE DATA BY LESSONS

\begin{tabular}{l|r|r|r|r|r|r|r|r|r|r|r|c}
\hline \multirow{2}{*}{ Date } & \multicolumn{4}{|c|}{ Feb } & \multicolumn{3}{c|}{ Mar } & \multicolumn{3}{c|}{ Apr } & May \\
\cline { 2 - 13 } & 1 & 8 & 15 & 22 & 1 & 15 & 29 & 5 & 12 & 19 & 26 & 3 \\
\hline Lesson number & 2 & 3 & 4 & 5 & 6 & 7 & 8 & 9 & 10 & 11 & 12 & 13 \\
\hline Conventional class & 55 & 35 & 30 & 23 & 24 & 23 & 19 & 21 & 21 & 21 & 19 & 18 \\
TV class & 20 & 41 & 45 & 37 & 48 & 49 & 47 & 46 & 45 & 42 & 41 & 37 \\
Absences & 6 & 5 & 6 & 21 & 9 & 9 & 15 & 14 & 15 & 18 & 21 & 26 \\
\% Conventional class & 68 & 43 & 37 & 28 & 30 & 28 & 23 & 26 & 26 & 26 & 23 & 22 \\
\% TV class & 25 & 51 & 56 & 46 & 59 & 60 & 58 & 57 & 56 & 52 & 51 & 46 \\
\% Absences & 7 & 6 & 7 & 26 & 11 & 11 & 19 & 17 & 19 & 22 & 26 & 32 \\
\hline
\end{tabular}

${ }^{1}$ Unusually high absenteelsm resulted from a blizzard on 21-22 February.

TABLE III

SUMMARY OF ATTENDANCE DATA

FOR THE SEMESTER

\begin{tabular}{lc}
\hline Total visits to conventional class & 309 \\
Total visits to TV class & 498 \\
Total visits to both classes & 807 \\
Percentage of visits that were TV & $62 \%$ \\
Total absences & 165 \\
Total visits and absences & 972 \\
Percentage of visits-absences that & \\
were TV & $51 \%$ \\
Total number of changes from one & \\
class to the other & 81 \\
\hline
\end{tabular}


For purposes of this discussion the students in the experimental sections were divided into two groups, "TV" students and "conventional" students. Those students who attended the TV class $50 \%$ or more of the times they attended either class are referred to as TV students or TV attenders; those students who attended the TV class less that $50 \%$ of the times they attended either class are referred to as conventional students or conventional attenders. (See Appendix $G$ for the percentage of visits to the TV class.)

The TV attenders who responded to the questionnalre (39 students) gave most often as reasons for attending the TV class that the TV class covered more material in less time and that the TV class did a better job of presenting the material, or some variation of these two reasons. Three students indicated that they did not like other students ${ }^{\circ}$ asking questions during the conventional class and taking up class time for themselves. One student put it quite tersely: "Some dummy would ask simple questions which took up the entire class's time.". Some students also liked the compactness and conciseness of the TV lessons. One student stated a rather interesting reason for attending the TV class, making one wonder how many others did the same thing, but did not admit it: ". . just started and didn't see any reason to change." One student stated as his reason that the TV class was "less threatening to me as a student." Exactly why he felt that the conventional class was a threat to him was not elucidatedl One student wrote on her questionnaire:

At first I chose not to go to TV, as I had had TV classes before and had found them boring, but I decided to try it and found that these TV lectures are not only interesting, but [also] informat ive. 
The conventional attenders who responded to the questlonnaire (19 students) also gave most often two reasons for attending the conventional class: it was possible to ask questions and it was more personal. (It is interesting to note that most of the students who said that they liked being able to ask questions never themselves asked questions in the conventional class.) Several also insisted that the IV lessons were boring.

of special interest is the fact that two international students responding to the questlonnalre satd that the. IV lessons were clearer and more easily understood by them than the conventional lessons. Perhaps the visualization of concepts in the IV lessons helps somewhat to bridge the language barrier.

Table IV contains a summary of the responses of the students to this particular part of the questlonnaire and the actual numbers of students giving specific responses.

\section{Some Interesting Inferences}

One of the questions on the last questionnaire asked the students whether they would rate their attltude toward instructional IV as havIng improved, deteriorated, or remained unchanged during the semester. of the students responding, $47 \%$ indicated that their attitude had improved; $4 \%$ sald that their attitude had deterlorated; and $42 \%$ felt that their attitude was unchanged. The rest were undecided.

During the semester $69 \%$ of the students became IV class attenders (attending the TV class 50\% or more of the times that they attended elther class) and $31 \%$ of the students became conventional class attenders (attending the IV class less than $50 \%$ of the times that they 
attended either class). When the students entered the course, $64 \%$ indicated on the pretest questionnalre a negative attitude toward instructlonal TV, while $19 \%$ Indicated a positive attltude and $17 \%$ were neutral. At the conclusion of the course only $27 \%$ expressed a negative attitude on the posttest questlonnalre toward instructional TV, wh1le $64 \%$ expressed a positive attitude and $9 \%$ were neutral.

TABLE IV

SUMMARY OF REASONS GIVEN BY STUDENTS FOR ATTENDING CLASSES AS THEY DID

\begin{tabular}{lcc}
\hline Reason given & Number & Percentage \\
\hline IV attenders (39 students responding) & & \\
\hline Covered more material faster & 18 & $46 \%$ \\
Better presentation of the material & 15 & $38 \%$ \\
Presentation more compact and concise & 5 & $13 \%$ \\
Too many. quest lons asked in conventional & 3 & $8 \%$ \\
class & 2 & $5 \%$ \\
More interesting & \\
Conventional attenders (19 students responding) & \\
Possible to ask questions as material was & 8 & $42 \%$ \\
presented : & 7 & $37 \%$ \\
More personal & 5 & $26 \%$ \\
TV boring & 2 & $11 \%$ \\
Material in TV lessons presented too fast & 2 \\
\hline
\end{tabular}

One may suppose then that for a fairly large number of students the TV series was considered successful by them as a teaching medium, and that it is possible to overcome some of the negative attitudes toward ITV with careful planning and careful attention to details 
based on the guidelines in Chapter III.

Another interesting bit of information came to light when the questionnaire that is given to all students enrolled in the course was analyzed. The same four questions referred to in Table I of Chapter I were examined and the responses of the students in the experimental section were compared with the responses of all of the students together. The results are shown in Table $v$, indicating that the students who had a cholce really did seem to prefer the TV classes as their attendance Indicated. One student wrote on her questionnaire that she never liked ITV until she had a cholce and could compare the TV with the conventional presentation. Then she became aware that the TV lessons were better organized and presented, and she preferred IV.

TABLE V

SOME RESULTS OF A GENERAL QUESTIONNAIRE GIVEN

TO ALL STUDENTS ENROLLED IN THE COURSE

WITH THE EXPERIMENTAL SECTION

TALLIED SEPARATELY

\begin{tabular}{lcc}
\hline & $\begin{array}{c}\text { Spring } 71 \\
\text { A11 } \\
\text { students }\end{array}$ & $\begin{array}{c}\text { Spring 71 } \\
\text { Experimental } \\
\text { section }\end{array}$ \\
\hline Attended class regularly & $93 \%$ & $83 \%$ \\
Thought TV lessons were informative & $67 \%$ & $64 \%$ \\
Thought TV lessons were Interesting & $35 \%$ & $45 \%$ \\
Expressed preference for TV class & $34 \%$ & $58 \%$ \\
\hline over conventional class & $34 \%$ & \\
\hline
\end{tabular}




\section{CHAPTER V}

\section{TESTING SOME HYPOTHESES}

\section{Some Assumptions}

When the experimental section was being planned and set up, there were certain intultive assumptions regarding outcomes. Based on past experience, it could be assumed that most students would probably have a negative attitude toward the use of instructional television and that they would initially choose the conventional class. It was hoped that the new TV series would be able to change their attitudes toward TV In a more positive direction. Based upon the experiments to which reference was made in Chapter II, it was assumed that most students would perform equally well in the course regardless of their choice of teaching method. That students would tend to be absent more from the TV class seemed a justifiable assumption. It was also assumed that the more dogmatic students would tend to choose the conventional class and would tend to exercise the freedom of cholce less. There was no particular assumption with regard to cumulative grade point average, although Mckeachie (22) cites a study in which students with higher ability tended to rate instructional TV lower than students of lower abiliity.

In order to determine whether some of these assumptions were correct, several hypotheses were stated and tested. Some additional data were required which were obtained and are shown in Appendix $H$. 
Seven dependent variables were used in the analyses of variance: (1) attitude toward instructional IV at the beginning of the course, as measured by the pretest questionnalre; (2) attitude toward instructional IV at the end of the course, as measured by the posttest questionnaire; (3) the change in attitude toward instructional IV from the pretest to the posttest, found by subtracting the pretest score from the posttest score and adding ten (1n order to prevent the occurence of negative numbers); (4) the performance in the course, as measured by the number of points earned in the course out of a posstble 102 points; (5) the number of absences during the semester after the students were given a cholce of classes to attend; (6) dogmatism; as measured by the Schulze Short Dogmatism Scale; and (7) the cumulative grade point average through the previous semester.

The first twelve hypotheses were treated by simple analysis of variance, while the last seven were analyzed using the Pearson productmoment coeffictent of correlation. All calculations were done on an IBM System/360, Model 65, computer, using the Blomedical Computer Programs contained in the Oklahoma State Untversity Computer Center Library.

\section{Prior ITV Exposure}

The students enrolled in the experimental section were divided Into țwo groups, those who had been exposed to instructional IV previously and those who had had no exposure to instructional TV. Five hypotheses were tested for this grouping.

For the first case, the null hypothesis is stated as follows: There is no signfficant relationshtp in attitude toward instructional 
IV as weasured by the pretest between those who had prior ITV exposure and those who did not have prior ITV exposure. The alternate hypothesis is stated as follows: There is a significant relationship in attitude toward instructional IV as measured by the pretest between those who had prior ITV exposure and those who did not have prior ITV exposure. The F-table in shown in Table VI.

\section{TABLE VI}

F-TABLE FOR PRIOR TV EXPOSURE AND PRETEST ATTITUDE

\begin{tabular}{lrrrrc}
\hline & Sum of Squares & DF & Mean Square & F Ratio & P \\
\hline Between groups & 32.8629 & 1 & 32.8629 & 7.1101 & $<0.025$ \\
Within groups & 365.1367 & 79 & 4.6220 & & \\
Total & 397.9995 & 80 & & & \\
\hline
\end{tabular}

The nuli hypothesis is rejected at the 0.025 confidence level. Students coming into the course with prlor ITV experience had a more negative attitude toward ITV than did students with no ITV exposure, the latter group having a higher mean score on the pretest.

For the second case, the null hypothesis is stated as follows: There is no significant relationship in attitude toward instructional TV as measured by the posttest between those who had prior ITV exposure and those who did not have prior IIV exposure. The alternate hypothesis is stated as follows: There is a signiflcant relationship in 
attltude toward Instructional IV as measured by the posttest between those who had prior ITV exposure and those who did not have prior ITV exposure. The F-table for this hypothesis is shown in Table VII.

TABLE VII

F-TABLE FOR PRIOR EXPOSURE AND POSTTEST .ATTITUDE

\begin{tabular}{lccccc}
\hline & Sum of Squares & DF & Mean Square & F Rat10 & P \\
\hline Between groups & 31.3285 & 1 & 31.3285 & 3.1904 & NS \\
Within groups & 707.0071 & 72 & 9.8195 & & \\
Total & 738.3354 & 73 & & & \\
\hline
\end{tabular}

The null hypothesis is accepted at the 0.05 confidence level. This indicates that the attitudes of students at the end of the course were not prejudiced by their prior exposure or lack of exposure to instructional TV. This may be interpreted to suggest that the att 1 tudes toward ITV with which students entered the course were not necessarlly carried through to the end of the course, and the IV series used in the course was evaluated on its own, rather than upon the students' prior experiences.

For the third case, the null hypothesis is stated as follows: There is no significant relationship in course performance between those who had prior ITV exposure and those who did not have prior ITV exposure. The alternate hypothesis is stated as follows: There is a significant relationship in course performance between those who had 
prior ITV exposure and those who did not have prior ITV exposure. The F-table is shown in Table VIII.

TABLE VIII

F-TABLE FOR PRIOR TV EXPOSURE AND COURSE PERFORMANCB

\begin{tabular}{lrrrrr}
\hline & Sum of Squares & DF & Mean Square & F Ratio & P \\
\hline Between 8roups & 212.5308 & 1 & 212.5308 & 0.5905 & NS \\
W1thin groups & 28075.3008 & 78 & 359.9397 & & \\
Totals & 28287.8281 & 79 & & & \\
\hline
\end{tabular}

The null hypothesis is accepted at the 0.05 confidence level. Prior exposure or lack of exposure to instructional TV was not related to the students' performance in the course.

For the fourth case, the nu1l hypothesis is stated as follows: There is no significant relationship in absenteeism between those who had prior ITV exposure and those who did not have prior ITV exposure. The alternate hypothesis is stated as follows: There is a significant relationship in absenteeism between those who had prior ITV exposure and those who did not have prior ITV exposure. The F-table is shown in Table IX.

The null hypothesis is accepted at the 0.05 confidence level. Prior exposure to ITV was not related to attendance, even though it might appear that a more negative attitude resulting from prior 
exposure would tend to support a higher rate of absenteelsm. of course, In this particular case, since the students had a choice of classes to attend, perhaps an Inclination to absent oneself from the TV class would be supplanted by attending the conventional class.

TABLE IX

F-TABLE FOR PRIOR TV EXPOSURE

AND ABSENTEEISM

\begin{tabular}{lccccc}
\hline & Sum of Squares & DF & Mean Square & F Ratio & P \\
\hline Bdtween 8roups & 4.3583 & 1 & 4.3583 & 0.6991 & NS \\
Within 8roups & 492.5286 & 79 & 6.2345 & & \\
Total & 496.8867 & 80 & & & \\
\hline
\end{tabular}

For the fifth case, the null hypothesis is stated as follows: There is no significant relationship in change of attitude toward ITV during the setiester between those who had prlor ITV exposure and those who did not have prior ITV exposure. The alternate hypothesis is stated as follows: There is significant relationship in change of attitude toward ITV during the semester between those who had prior ITV exposure and those who did not have prior ITV exposure. The Ftable is shown in Table $X$.

The null hypothesis is accepted at the 0.05 confidence level. The change in attitude toward instructional TV was not related to prior exposure or lack of prior exposure to ITV. Again this suggests that the attitudes toward IIV with which students come into the course were 
not necessarily carried through to the end of the course, and the attitudes changed during the semester for both groups at the same rate.

TABLE $X$

F-TABLE FOR PRIOR TV EXPOSURE AND CHANGE IN ATTITUDE FROM PRETEST TO POSTTEST

\begin{tabular}{lccccc}
\hline & Sum of Squares & DF & Mean Square & F Rat10 & P \\
\hline Between groups & 0.2961 & 1 & 0.2961 & 0.0285 & NS \\
W1thin groups & 747.7141 & 72 & 10.3849 & & \\
Total & 748.0100 & 73 & & & \\
\hline
\end{tabular}

In summary, the hypotheses tested agalnst prior exposure to IIV or lack of exposure to ITV all show no slgniflcance, except for the att1tude toward IIV with which students entered the course, with students having been exposed to ITV having a more negative attitude.

\section{Type of Attenders}

For the next group of hypotheses, the students were divided into two groups, those who attended the IV class $50 \%$ or more of the times that they attended elther class (designated as "IV attenders") and those who attended the IV class less than $50 \%$ of the times that they attended either class (designated as "conventional attenders"). Seven hypotheses were tested for this grouping.

For the first case, the null hypothesis is stated as follows: There is no significant relationship in attitude toward IIV as measured 
by the pretest between the IV attenders and the conventional attenders. The alternate hypothesis is stated as follows: There is a significant relationship in attitude toward ITV as measured by the pretest between the IV attenders and the conventional attenders. The F-table is shown In Table XI.

TABLE XI

TYPE OF ATTENDER AND PRETEST ATTITUDE

\begin{tabular}{lccccc}
\hline & Sum of Squares & DF & Mean Square & F Ratio & P \\
\hline Between groups & 11.1607 & 1 & 11.1607 & 2.2792 & NS \\
Within groups & 386.8386 & 79 & 4.8967 & & \\
Total & 397.9993 & 80 & & & \\
\hline
\end{tabular}

The null hypothesis is accepted at the 0.05 confidence level. The attitude toward instructional IV with which most students came into the course was not related to their overall attendance to the TV classes. This suggests that their initial attitudes did not necessarily carry over to the end of the course, but that they attended the class of their cholce based upon the imadiate situation rather than upon prior attitudes.

For the second case, the null hypothesis is stated as follows: There is no significant relationship in attitude toward ITV as measured by the posttest between the IV attenders and the conventional attenders. The F-table is shown in Table XII. 
The null hypothesis is rejected at the 0.001 confidence level. The attitudes toward instructional TV in the TV class as given on the posttest questionnalre were indeed reflected in their cholce of classes. The TV attenders had a higher mean, having had a better attitude at the end of the course than the conventional attenders. This gives substance to the assumption that the behavioral response to the cholce is a good indicator of attitude toward the alternatives of the choice. Again there is the suggestion that attitudes did change during the senester, since attendance was related to the attitude at the end of the course and not at the beginning.

TABLE XII

TYPE OF ATTENDER AND

POSTTEST ATTITUDE

\begin{tabular}{lcccccc}
\hline & Sum of Squares & DF & Mean Square & F Ratio & P \\
\hline Between groups & 368.1924 & 1 & 368.1924 & 71.6203 & $<0.001$ \\
W1thin groups & 370.1445 & 72 & 5.1409 & & \\
Total & 738.3369 & 73 & & & \\
\hline
\end{tabular}

For the third case, the null hypothesis is stated as follows: There is no significant relationship in change of attitude from the pretest to the posttest between the IV attenders and the conventional attenders. The altermate hypothesis is stated as follows: There is a significant relationship in change of attitude from the pretest to the posttest between the IV attenders and the conventional attenders. 
The F-table is shown in Table XIII.

TABLE XIII

TYPE OF ATTENDER AND CHANGE IN ATTITUDE

FROM PRETEST TO POSTTEST

\begin{tabular}{lccccc}
\hline & Sum of Squares & DF & Mean Square & F Rat lo & P \\
\hline Between groups & 276.3748 & 1 & 276.3748 & 42.1912 & $<0.001$ \\
WIth1n groups & 471.6377 & 72 & 6.5505 & & \\
Total & 748.0125 & 73 & & & \\
\hline
\end{tabular}

The null hypothesis is rejected at the 0.001 confidence level. The students attending the IV class had a higher mean, showing a greater change in attitude than did those attending the conventional class. The change in attitude was toward a more favorable response to the use of TV.

For the fourth case, the null hypothesis is stated as follows: There is no significant relationship in course performance between the TV attenders and the conventional attenders. The alternate hypothesis is stated as follows: There is a signiflcant relationship in course performance between the TV attenders and the conventional attenders. The F-table is shown in Table XIV.

The null hypothesis is accepted at the 0.05 confidence level. The students in both groups performed equally well.

For the Elfth case, the null hypothesis is stated as follows: There is no significant relationship in absenteeism between the IV 
attenders and the conventional attenders. The alternate hypothesis is stated as follows: There is a significant relationship in absenteeism between the IV attenders and the conventional attenders. The $\mathrm{F}$-table is shown in Table XV.

TABLE XIV

TYPE OF ATTENDER AND

COURSE PERFORMANCE

\begin{tabular}{lccccc}
\hline & Sum of Squares & DF & Mean Square & F Ratio & P \\
\hline Between groups & 118.4727 & 1 & 118.4727 & 0.3280 & NS \\
W1thin groups & 28169.3789 & 78 & 361.1458 & & \\
Total & 28287.8516 & 79 & & & \\
\hline
\end{tabular}

TABLE XV

TYPE OF ATTENDER AND

ABSENTEEISM

\begin{tabular}{lccccc}
\hline & Sum of Squares & DF & Mean Square & F Ratio & P \\
\hline Between groups & 2.0318 & 1 & 2.0318 & 0.3244 & NS \\
Within groups & 494.8552 & 79 & 6.2640 & & \\
Total & 496.8870 & 80 & & & \\
\hline
\end{tabular}

The null hypothesis is accepted at the 0.05 confidence level. Students did not tend to be absent more from the IV class than from the conventional class; absenteelsm was not related to which class the 
students were choosing to attend when they did attend.

For the sixth case, the null hypothesis is stated as follows:

There is no significant relationship in dogmatism between the TV attenders and the conventional attenders. The alternate hypothesis is stated as follows: There is a significant relationship in dogmatism between the IV attenders and the conventional attenders. The F-table is shown in Table XVI.

TABLE XVI

TYPE OF ATTENDER AND

DOGMATISM

\begin{tabular}{lccccc}
\hline & Sum of Squares & DF & Mean Square & F Rat10 & P \\
\hline Between groups & 17.9352 & 1 & 17.9352 & 0.1995 & NS \\
Within groups & 6474.0469 & 72 & 89.9173 & & \\
Total & 6491.9805 & 73 & & & \\
\hline
\end{tabular}

The null hypothesis is accepted at the 0.05 confidence level. The more dogmatic students did not show a greater tendency to attend the conventional class or the IV class.

For the seventh case, the null hypothesis is stated as follows: There is no significant relationship in cumulative grade point average (GPA) between the TV attenders and the conventional attenders. The alternate hypothesis is stated as follows: There is a significant relatlonship in cumslative grade point average (GPA) between the IV attenders and the convent lonal attenders. The F-table is shown in Table XVII. 
TABLE XVII

TYPE OF ATTENDER

AND GPA

\begin{tabular}{lccccc}
\hline & Sum of Squares & DF & Mean Square & F Rat10 & P \\
\hline Between groups & 0.3317 & 1 & 0.3317 & 0.8857 & NS \\
Within groups & 24.3464 & 65 & 0.3746 & & \\
Total & 24.6781 & 66 & & & \\
\hline
\end{tabular}

The null hypothesis is accepted at the 0.05 confidence level. GPA was not a factor in the students' cholces.

In summary, only the posttest attitude toward instructional TV and the change in attitude from the pretest to the posttest were significantly related to whether the students were TV attenders or conventional attenders. The IV attenders had a better attitude toward TV than did the conventional attenders; and they also showed a greater change in attitude toward IV than the conventional attenders, change in attitude being toward a more favorable attitude toward TV.

\section{Changes in Clags Attendance}

Some additlonal hypotheses were tested using the Pearson productmoment coefficient of correlation. The correlation matrix obtained from the computer program is shown in Table XVIII. These tests were in order to determine whether the number of times students changed from ic

one class to the other was correlated with other variables.

For the first case, the null hypothesis is stated as follaxs:

There is no significant correlation between the number of times students 
TABLE XVIII

CORRELATION MATRIX

\begin{tabular}{lcccccc}
\hline & $\begin{array}{c}\text { Course } \\
\text { performance }\end{array}$ & $\begin{array}{c}\text { Grade point } \\
\text { average }\end{array}$ & Dogmatism & $\begin{array}{c}\text { Attitude, } \\
\text { posttest }\end{array}$ & $\begin{array}{c}\text { Attitude, } \\
\text { pretest }\end{array}$ & $\begin{array}{c}\text { Times } \\
\text { changed }\end{array}$ \\
\hline Times changed & 0.01777 & 0.05479 & -0.12290 & 0.15040 & 0.12972 & 1.00000 \\
Attitude, pretest & -0.01560 & -0.20284 & -0.01971 & 0.18016 & 1.00000 & \\
Attitude, posttest & 0.48770 & -0.17574 & 0.48394 & 1.00000 & & \\
Dogmatism & 0.37863 & -0.07636 & 1.00000 & & & \\
Grade point average & 0.02791 & 1.00000 & & & & \\
Course performance & 1.00000 & & & & & \\
\hline
\end{tabular}


changed from one class to the other and grade point averages (GPA). The alternate hypothesis is stated as follows: There is a significant correlation between the number of times students changed from one class to the other and grade point averages (GPA). With a correlation coefficlent of 0.05479 , the null hypothesis is accepted at the 0.05 confidence level.

For the second case, the null hypothesis is stated as follows: There is no significant correlation between the number of times students changed from one class to the other and attitude toward ITV as measured by the pretest. The alternate hypothesis is stated as follows: There is a significant correlation between the number of times students changed from one class to the other and attitude toward ITV as measured by the pretest. With a correlation coefficient of 0.12972 , the null hypothesis is accepted at the 0.05 confidence level. For the third case, the null hypothesis is stated as follows: There is no significant correlation between the number of times students changed from one class to the other and attitude toward ITV as measured by the posttest. The alternate hypothesis is stated as follows: There is a significant correlation between the number of times students changed from one class to the other and attitude toward ITV as measured by the posttest. With a correlation coefficient of 0.15040 , the null hypothesis is accepted at the 0.05 confidence level.

For the fourth case, the null hypothesis is stated as follows: There is no significant correlation between the number of times students changed from one class to the other and performance in the course. The alternate hypothesis is stated as follows: There is a significant correlation between the number of times students changed 
from one class to the other and performance in the course. With a correlation coefficient of 0.1777 , the null hypothesis is accepted at the 0.05 confidence level.

For the fifth case, the null hypothesis is stated as follows: There is no significant correlation between the number of times students changed from one class to the other and dogmatism. The alternate hypothesis is stated as follows: There is a significant correlation between the number of times students changed from one class to the other and dogmatism. With a correlation coefficient of -0.12290 , the null hypothesis is accepted at the 0.05 confidence level.

In summary, the number of times students changed from one class to the other is not significantly correlated with course performance, GPA, dogmatism, pretest attitude toward ITV, or posttest attitude toward ITV.

\section{Attitude and Performance}

Of interest also is whether there is any correlation between pretest attitude toward ITV and performance in the course and posttest attitude toward ITV and performance in the course.

For the first case, the null hypothesis is stated as follows: There is no significant correlation between attitude toward ITV as measured by the pretest and course performance. The alternate hypothesis is stated as follows: There is a significant correlation between attitude toward ITV as measured by the pretest and course performance, With a correlation coefficient of -0.01560 , the null hypothesis is accepted at the 0.05 confidence level.

For the second case, the null hypothesis is stated as follows: 
There is no significant correlation between attitude toward ITV as measured by the posttest and course performance. The alternate hypothesis is stated as follows: There is a significant correlation between attitude toward ITV as measured by the posttest and course performance. With a correlation coefficient of 0.48770 , the null hypothesis is rejected at the 0.001 confidence level. The more positive students' attitudes toward ITV at the end of the course were, the better their performance in the course. 
CHAPTER VI

\section{SUMMARY AND CONCLUSIONS}

A new instructional television series for a beginning computer programing course was prepared, using a new format that was designed to be both informative (presented in a well organized, meaningful, clear, and concise manner) and interesting (gaining and maintaining close attention) and making use of special capabilities of the television medium. A television series so designed should overcome to some extent the negative attitudes of students toward the use of instructional television.

An experimental section of the course was set up during a semester in which the students were given a choice of attending a television lesson or a conventional lecture covering the same material. During the semester $69 \%$ of the students became TV class attenders (attending the TV class $50 \%$ or more of the times that they attended either class) and $31 \%$ of the students became conventional class attenders (attending the TV class less than $50 \%$ of the times that they attended elther class). As measured by the pretest questionnaire, the posttest ques tionnaire, and the attendance data, the attitudes of the students did change during the semester and became less negative toward TV.

Statistical analysis of the attendance data indicated that the types of attenders that the students became were unrelated to their pretest attitudes, but were significantly related to their posttest 
attitudes. The attitudes with which the students entered the course did not necessarily determine whether they chose to become TV attenders or conventional attenders. Once they had become IV attenders or conventional attenders, however, their attitudes toward instructional TV were reflected in their attendance records. Thus, giving the students an open-ended cholce seems to be a good way of obtaining a behavioral measure of attitude toward the alternatives.

The new TV series can be sald to be successful, accomplishing to a satisfactory extent the initial objectives of producing a series that would elicit a more favorable response from the students. There are refinements in content and method that should be made, however, in order to accomplish the objectives more fully. There are places in which the material is not clear, and there are parts that are certainly less than stimulating. But the approach as outlined in Chapter III is demonstrated to be sound, and, with additional refinements in executing the procedure, could be quite successful.

Instructional television at the college level can be used effeco tively as a teaching medium, provided that the unique capabilities ino herent in television are used to their fullest. In general, instruc. tlonal TV should not be used just for transporting a conventional leco ture; it should be used with an attitude of creativity and innovation within the framework of what television can and cannot do for the teaching-learning process. 


\section{A SELECTED BIBLIOGRAPHY}

(1) Barnard, W. Robert, Lagowski, $\mathrm{J}_{\circ} \mathrm{J}_{\circ}$, and $0^{\circ}$ Connor, Rod。 "The Modo em Chemistry Classroom." Journal of Chemical Education Vol. 45 (1968), 63-70。

(2) Becker, Samuel L。 "Interest, Tension, and Retention" AV Commun ication Review, Vol。12 (1964), 277-291。

(3) Blenheim, Laurence C. "TV Teaching by Professional Performers?" AV Communication Review, Vol. 17 (Fall, 1969), 322-326.

(4) Callaci, Charles. "Producing and Directing the Television Lesson." Educational: Irstructional Broadcasting, Vol. 2 (January, 1969), 30-32.

(5) Chu, Godwin $C_{0}$, and Schramm, Wilbur, Learning From Television. Washington: National Assoclation of Educational Broado casters, 1967。

(6) Dlamond, Robert M。 A Gulde To Instructional Television. New York: MCGraw-Hī1 $\overline{1,1964 。}$

(7) Garland, John $K_{0}$ "Training For Teaching Assistants。" Journal of Chemical Education, Vol. 46 (1969), 621.

(8) Gilkey, Richard。 "TV: A Medium In Transition。" The Clearing House, Vol, 44 (Apri1, 1970), 510-512.

(9) GIII, Jack E。 "ITV: Move Up or Move Outg" AV Guide, Vol. 48 (May, 1969), 10-11.

(10) Gropper, George L. "Does "Programmed" Television Need Active Responding?" AV Communication Review, Vol. 15 (Spring, 1967), 5-22。

(II) Gross, Lynne So "Utilizing ITV For Perfoxmance Classes." Audio. visual Instruction, Vol。14 (November, 1969), 54059

(12) Gryde, Stanley $K_{0}$ "The Feasibility of "Programmed" TV Instruc. tlon." AV Communicarion Review, Vol。14 (Spring, 1966), 71089 。

(13) Guba, Egon Gos and Snyder, Clinton A, "Instructional TV and the Class room Teacher。" AV Communication Review, Vol。13 (1965)。 $5 \cdot 27$. 
(14) Harrington, Robert $W_{0}$, and Knoblett, James $A_{0}$ "Instructional ClosedoCircuit Television: A Case Study." The Joumal of Educational Research, Vol。 62 (September, 1968), $\overline{40-45 .}$

(15) Hauser, Rick。 "The ITV Humanities Project." Audiovisual Instruction, Vol. 13 (January, 1968), 31-34.

(16) Humphreys, D. Ao, and Tomlinson, R. H. "Closed Circult Televio sion In Freshman Laboratories." Journal of Chemical Education, Vol. 46 (1969), 618-620。

(17) Janes, Robert W. "Preexisting Attitudes of College Students to Instructional Television" AV Communication Review, Vol。 12 (1964), 325-336.

(18) Kanner, Joseph $H_{0}$ "Teaching by TV in the Army - An Overv 1 ew。" AV Communication Review, Vol。16 (Summer, 1968), 178-187。

(19) Korn, Harold A。, and Giddan, Norman S. "Scoring Methods and Con。 struct Validity of the Dogmatism Scale." Educational and Psychological Measurement, Vol. 24 (1964), 857-874.

(20) Kucera, Goeffrey. "TV In Teacher-Training: It Works at Untvero sity of Hawail." Educational Perspectives, Vol。 7 (October, 1968), 28.31.

(21) Lawrence, George L. "Resource Television in Teacher Education," Audiovisual Instruction, Vol。 13 (November, 1968), 997-998。

(22) Mckeachie, Wilbert $J_{0}$ "Research on Teaching at the College and University Level." Handbook of Research on Teaching. Ed. No L。 Gage. Chicago: Rand McNally, 1963, Pp. 1118.1172.

(23) Meyer, Richard J。 "Charles A。 Siepmann and Educational Broado casting." AV Communication Review, Vol。12 (1964), 413-430,

(24) Meyer, Richard J. "Critlcal View of TV and Higher Education."

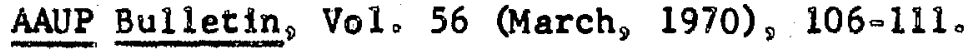

(25) Montgomery, John A. "ITV Programming - Make or Buy?" Educational TV, Vol. 2 (January, 1970), 16 20 。

(26) Moss, Leonard. "Evaluation of a TV Course" The Educational Forum, Vol. 34 (March, 1970), 401-406。

(27) Neidt Charles 0 . "Use of VIdeotaped Instructional Television For Teaching Study Sk11 is in a University Setting " AV Communication Review, Vol. 15 (Fall, 1967), 269-284。

(28) Nelson, Gregoxy V。 "Instant TV Replay In the Lecture Hall。" Journal of Chemical Education. Vol. 46 (1969), 620 . 
(29) Ohlinger, John. "What Makes a Good ITV Program?" Educationa1 IV, Vo1. 2 (January, 1970), 14-15, 20.

(30) 0liphant, Robert. "Instructional TV and Programed Learning." Journal of Higher Education, Vol. 35 (1964), 488-492.

(31) Ostle, Bernard. Statistics in Research, 2nd ed. Ames: The Iowa State University Press, 1963.

(32) Rawls, James R., and Rawls, Donna J. "Evaluation of ClosedCircuit Television in Teaching Educational Psychology." Psychological Reports, Vol. 22 (1968), 1041-1044.

(33) Rayder, Nicholas F., and Neidt, Charles o. "Attitude Change as a Function of Scales Administered." AV Communication Review, Vol. 12 (1964), 402-412.

(34) Robinson, John P., and Shaver, Phillip R. Measures of Social Psychological Attitudes. Ann Arbor: Survey Research Center, Institute for Social Research, University of Michigan, 1969.

(35) Rokeach, Milton. "The Nature and Meaning of Dogmatism." Psychological Review, Vol. 61 (1954), 194-204.

(36) Rokeach, Milton. The Open and Closed Mind. New York: Basic Books, 1960.

(37) Schulze, R. H. K. "Shortened Version of the Rokeach Dogmatism Scale." Journal of Psychological Studies, Vo1. 13 (1962), 93-97.

(38) Siepmann, Charles A. "ITV in Perspective - A Reappraisal." Educational TV, Vol. 2 (January, 1970), 11-13.

(39) Siepmann, Charles A. "The Sleeping Giant . . . ITV in Higher Education." Educational TV, Vol. 2 (May, 1970), 13-15, 20.

(40) Skinner, Ray, Jr. "A New Format for ITV." AV Communication Review, Vol. 16 (Fall, 1968), 287-293.

(41) Tyler, I. Keith. "Educational Implications of the TV Medium." AV Communication Review, Vol. 12 (1964), 61-74.

(42) Wade, Serena W. "Effects of TV Utilization Procedures on Learning." AV Communication Review, Vol. 17 (Fall, 1969), 283-290.

(43) Williams, Catharine M. "Reexamination of 'No Significant Differences'. That ITV Studies Report." AV Communication Review, Vol. 10 (1962), 263-265.

(44) Wolfe, Roger. "Televised Teaching Vs. Television Teaching." Educational TV, Vo1. 2 (April, 1970), 13-14. 


\section{APPENDIX A}

\section{OUTLINE OF THE TV LESSONS}

I. Lesson 1: Programing Fundamentals

A. Digital computing devices

1. Abacus

2. Hands

3. Modern high-speed electronic digital computers

B. The frontage problem

1. Algebriac notation of problem

2. Solution using computer

C. Compller and comptle phase

D. Execution

E. Building the program

1. Assignment statements

2. END - compl lation error

3. STOP - execution error

4. WRITE

5. FORMAT

6. Complete program

F. Order of execution

1. Executable statements

2. Nonexecutable statements

G. FORTRAN names 
H. Arithmetic operators
I. FORTRaN punched cards
J. Punching and running a program

II. Lesson 2: Input and Output Instructions

A. Review of the frontage problem

B. WRITE statement in detail

C. Fomsat statemant in detail

1. T-type numbers

2. Fields

3. Number of digits to the right of the decimal point

4. Right-justified

5. Pw.d

6. Line printer code, 140

D. Writing three numbers

1. (1HO, F10.1)

2. (1H0,3F10.1)

E. READ statement

1. Data cards

2. Decimal point punched and not punched

3. Blank fields

III. Lesson 3: Decision-Making Instructions

A. Games and flow charts

1. Transfer and looping

2. Writing a program for playing a simple game

B. Integer numbers and names and I-specification

C. Running sums

D. Computed 60 TO statement 
E. Unconditional Go To statement

F. Hollerith strings, output

G. Arithmetic IF statement

IV. Lesson 4: Looping

A. Flow chart for table of squares and square roots

B. Loop counter: initial value, increment, and test

C. FORTRAN-supplied subprograms - SQRT $(Y)$

D. Exponentiation operator

E. X-specification, output

F. Continuation card

G. Do statement and CONTINUE statement

H. General program for making table

V. Lesson 5: Single-Dimensional Arrays

A. Definitions of array and subscript - DIMENSION statement

B. The maximum temperature problem

C. Input of array

1. Using Do

2. Using Implied DO

3. New record $(/)$, input

4. A-specification, input

5. Nested parentheses in FORMAT

6. X-specification, Input

D. Algorithm for finding maximum element of an array

1. Definition of algorithm

2. Explanation of the algorithm

E. Output of array

1. Using DO 
2. Using Implied DO

3. New record $(/)$, output

4. A-specification, output

5. Nested parentheses in FORMAT

F. Test data for program

VI. Lesson 6: The Dean's List (A Review)

A. A program to complle the Dean's L1st

B. INTEGER statement

C. I/0 of entire arrays

D. Integer arithmetic

VII. Lesson 7: Two-Dimensional Arrays

A. Table manipulation problem

B. Concept of "by rows" and "by columns"

C. Input of two-dimensional array

1. Using nested Do statements

2. Using nested $1 \mathrm{mplled} D O$

3. By columns and by rows

4. Including alphameric data

D. Manipulation of two-dimenslonal array

1. By rows

2. By columns

E. Output of two-dimensional array

1. Using nested Do statements

2. Using nested implied DO

F. DATA initialization statement (alphamerlc data)

VIII. Lesson 8: Logical Operations

A. Logical IF statement 
1. Relational operators

2. Examples with flow charts

3. Logical operators and compound arguments

4. Truth tables for .NOT., .AND., and .OR.

B. Logical data - the "plumbing" problem

1. LOGICAL statement

2. L-spectification

3. Logical expressions

IX. Lesson 9: FORMAT statements

A. Input

1. Numertc fields

a. Integer data

b. Real data
(1) F-type
(2) E-type

2. Alphamertc flelds
a. A-type
b. H-type (Hollerith)
C. Use of apostrophes or single quotes

3. Posttional spectfications
a. X: blank columns
b. T: "tabulator"
c. I: new record (data card)

B. Output

1. Numerlc flelds
a. Integer data
b. Real data 


$$
\begin{aligned}
& \text { (1) F-type } \\
& \text { (2) E-type }
\end{aligned}
$$

2. Alphameric Elelds

a. A-type

b. H-type (Holler1th)

c. Use of apostrophes or single quotes

3. Positional specifications

a. Horizontal (across page)

(1) X: blank columns

(2) T: "tabulator"

b. Vertical (down page)

(1) /: new record (1ine)

(2) Printer "line-skipping" codes
(a) Single-spacing
(b) Double-spacing
(c) New page
(d) Printing on current line (overprinting)

c. Grouping in FORMAT statements

X. Lesson 10: Subprograms I - FUNCTION Subprograms

A. Concept of subprograms

1. FORTRAN-supplied subprograms

2. User-8upplied subprograms

3. Using subprograms
a. Invoking the name
b. Passing the arguments
c. Executing the subprogram
d. Returning the "answer" 
B. Making the maximum algorithm into a FUNCTION

1. FUNCTION statement - arguments

2. RETURN statement

C. Calling statement

XI. Lesson 11: SUbprograms II - SUBROUTINE SUbprograms

A. The frequency counter problem

B. SUBROUTINE subprogram for frequency count

1. SUBROUTINE statement

2. Arguments

C. CALL statement

D. COMMON storage

E. CALL EXIT

XII. Lesson 12: Subprograns III - Graphic Output

A. Introduction to graphic types of line printer output

B. Problem of making a histogram on the line printer

C. SUBROUTINE for printing histogram, given frequency counts

1. User-supplled error messages for "bad" data

2. Vartable FORMAT

3. Debugging program for testing

D. Adding SUBRoutiNe from Lesson 11 and maln program

XIII. Lesson 13: Tasty Leftovers

A. Stngle statement functions (review of subprograms)

B. DOUBLE PRECISION

C. Assigned GO TO statement (revlew of condttional transfer statements)

D. Sorting algorithms - the interchange sort 
APPENDIX B

\section{A SAMPLE SCRIPT FOR A TV LESSON}

The following script was used for Lesson 1, making use of two instructors and an assistant to work the props.

Eugene Bailey is the first instructor for this particular lesson, and Ellen Wood is the second instructor. Seymour is the name given to the off-camera volce, which is used for teaching the syntax and form of the language, as well as for emphasizing important points that require special attention. Carl Provence, who served as the second instructor in several of the lessons, worked the props for this lesson. 
COMSC 2112, LESSON 1

PROGRAMMING FUNDAMENTALS

With

Eugene Batley and Ellen Wood

EUGENE: This is a Chinese abacus, an ancient and versatile computing device. With this instrument we can add, subtract, multiply, and divide. The abacus is one of the earliest of the man-made digital computing devices. Suppose that I want to find the sum of the numbers 1 through 10 . [Sums numbers on abacus.]

The sum of the numbers 1 through 10 is 55 . In effect, I simply counted out the beads of the abacus one at a time as I added the numbers - one digit at a time. Consequently, the abacus is called a digital computing device.

Can you think of a very simple digital computing device? You have at least one with you right now. Iry your hands and fingers. For example, I can add 5 and 3 and get 8. Again I counted up the digits one at a time; my fingers constitute a digital computing device.

Visual super: hand and the word "digital"

But, of course, my hands and fingers cease to be useful if I want to find the sum of the numbers 125 and 250 . I run out of 
fingers too quickly. But with the abacus this problem is simple. [Adds 125 and 250 to get 375.] The answer is 375. But suppose that I want to handle all the detalls of the national budget, or keep all the Information on students enrolled in a university, their class schedules, grades, grade points, etc. For elther of these massive problems the abacus is of little value to me. Such a vast amount of information would spl11 off the end of my abacus almost immediatelyl Besides that, the abacus, like the hands and fingers, cannot be used to store and recall vast amounts of information, do computational operatlons, and accomplish all of this at the snap of a flnger - or even in less time. Such a device is the modern high-speed electronic digital computer.

Movie Showing the computer room

This is a typical high-speed electronic digital computer with some of its supporting equipment. The actual computing or data processing part, known as the central processing unit, is capable of performing millions of operations per second as well as storing and retrieving millions of units of information in the memory unit, shown behind the operator's console. The central processing unit also controls the entire operation of the computer system. Most of the rest of the equipment that you see in the room is used for putting information into the central processing unit and for getting it back out.

[Walks to terminal.]

Here we have a typewriter terminal connected to the computer that you fust saw by an ordinary telephone. [Shows phone and acoustic coupler.] With this device we have direct access to the computer very conveniently anywhere there is a telephone, and we have all the power and versatility of the computer 1iterally at 
our fingertips.

[Sits at terminal.] I'll tell the computer that you're here. [Types following and gets responses.]

BB : Hello, Computer.

IBM: Hello, User 25. Please tell me your name.

EB: My name is Eugene Balley.

IBM: Your name is Eugene Bailey. There are other people with you. Who are they?

EB: My assistants, Ellen Wood and Carl Provence, and some students.

IBM: Hello, Mrs. Wood, and hello Mr. Provence, and a special welcome to the students!

EB : Thank you.

IBM: You're welcome.

of course, the computer can do only what it is told to do. It is not some mysterious device that thinks. I programmed the computer attached to this terminal to converse with the; I programmed the responses myself. Incidently, the part of the computer that I am using here is sald to be in the conversational mode. This is a spectal capability that this typewriter terminal and the computer provide.

This demonstration is stmply to show you one of the many capabilities of the computer avallable to the user. In this particular course, we w11l be teaching you one way to program an electrontc computer so that you can make it work for you.

The purpose of this course is to introduce fundamental concepts of a particular programing language. We will not even 
attempt to tell you all the details. Rather you should refer to a programmer's manual or to other materials for details. It will probably be better if you do not attempt to take many notes; just watch and 11sten.

Wel1, let's start. We're going to begin with a ridiculously simple problem, which is not intended to insult your intelilgence. I have deliberately chosen a problem so simple that the problem Itself will not be a barrier in your understanding of what we w111 be doing.

Ellen, will you please state the problem?

ELLEN: Suppose that I have bought a plece of property in a business district and the property is on a corner, facing onto two streets. The bullding 1 s 75.5 feet on the west side and 180.0 feet on the south side.

Visual Model of the bullding, Carl polnting

I'd Iike to know just how much of the bullding faces on the two streets, or in other words, how much frontage the bullding has. of course, all I have to do is just to add the number of feet on the west side, 75.5 , to the number of feet on the south side, 180.0 .

[Camera on Ellen.] I think that all of you can understand this problem and how to solve it. Now, I will put the problem on the magnet1c board in some clear and conventent form that everyone can understand.

Let's call the west side "W" and put Wm75.5 on the board. Then call the south side " $S$ " and put $S-180.0$ up. Then we add the 
two numbers together, calling the frontage "gw": FWW+S.

[Board now contains $\quad W=75.5$

$S=180.0$

$F=W+S \quad]$

That's simple enough, Bugene.

EUGENE: Yes, it 1s. Now, how can we get the computer to work the problem for us? That's the next question. Well, I'm going to get the answer using the computer. To do this, I will simply type the information on the board into the computer, adding some additional necessary instructions for the computer, which we will investigate in detall later. [Types into terminal: $\quad W=75.5$ $S=180.0$ $\mathrm{F}-\mathrm{W}+\mathrm{S}$ WRITE $(6,1) \mathrm{F}$

1 BORMAT (1HO, F10.1)

STOP

END

Computer output:

$W=75.5$

$S=180.0$

$\mathrm{F}=\mathrm{W}+\mathrm{S}$

WRITE $(6,1) \mathrm{F}$

1 FORMAT (1HO, F10.1)

STOP

END

EXECUTION

255.5

EXECUTION COMPLETED ]

And there is the answer, the sum of $W$ and $S, 255.5$.

[Camera to Eugene.] Let's try to understand what happened and what those additional statements that I typed in are for. I'11 begin by telling you to read the information on this card for me, and do what it says.

Visual7 Camera card with Thal writing on it 
Unless you are familiar with the Thai language, and assuming that my Thai writing is correct, you're having a little trouble, aren't you? I will have it translated for you.

SEYMOUR: Touch your toes five times.

VIsual Super: Touch your toes five times.

EUGENE: You see, the point I'm trying to make is this. You couldn't do what the writing on the card told you to do until someone translated it for you. The computer is going to have a similar problem. The information that Ellen put on the board is meaningful to us, but it is not meaningful to the computer and its electronic gear in its present form. The information that is meaningful to us must be translated into information that is meaningful to the computer.

This problem of translating is solved by making the computer do double duty for us by having it translate the information that is meaningful to us into information that is meaningful to it. The manufacturer of the computer provides the translating program with the computer; this translating program 1s called a compller.

SEYMOUR: The compiler is a translating program that translates Information that is meaningful to us into information that is meaningful to the computer.

\section{VIsual Illustrating the complier}

EUGENE: So, in order to have the computer work our problem, our procedure must be to write a set of Instructions, called a program, In a language that is meaningful to us and also to the trans- 
lating program or compller.

Let's take another look at what Ellen put on the board. [Camera to board.] This is a set of instructions that are meanIngful to us for solving the problem; it is a program. This program, as it stands, is also written in the FORTRAN language VIsual Super: FORTRAN

for which there is a compller to translate the set of instructions into Instractions meaningful to the computer. The FORTRAN language closely resembles the English language and also the symbolism of algebra. The computer takes our FORTRAN program, translates or complles

IVIsual Super: Complles

it with the FORTRAN compller, and then executes

VIsual Super: Executes

the set of instructions provided by the compiler.

So every job that we run on the computer requires a two-fold operation by the computer: compliling or translating the program and then executing the program.

Now let's bulld the complete FORTRAN program for this part1cular problem, starting with the first three instructions or statements, so that you will be able to see what the statements that I added mean.

Let's see what happens if I use only the first three statements that are on the board as my program. 
[Types into terminal: $\begin{aligned} & W=75.5 \\ & S=180.0 \\ & F=W+S\end{aligned}$

and runs on computer, mentioning compling.

Computer output : $\quad W=75.5$

$S=180.0$

$\mathrm{F}=\mathrm{W}+\mathrm{S}$

**ERROR**END STATEMENT MISSING** ]

The compller was translating the program, but it ran into difflculty. Here's what happened. I gave the compiler an Incomplete set of Instructions in that I didn't tell it when to end the translation phase and to begin the execution phase. In other words, the compller must be told when its job is completed, that is, when there are no more FORTRAN statements to translate. Let me 11 lustrate the problem this way. Suppose that you are walting at a rallroad crossing for a train to pass.

VIsual Train passing; END on caboose

What would be your cue that the train is passed so that you could cross the tracks? Obviously, the caboose, which is the last car of the train. When it is passed, then you can cross the tracks. Similarly, the compller must have a cue when all the FORTRAN statements have been translated so that it can begin the execution of the program. The "caboose" statement for the compller's cue is the END statement. Just as the caboose signifies the last car of the train, so the END statement signifies the last statement of the FORTRAN program.

SEYMOUR: The END statement marks the end of the compliling of the program or the translating of the program into machine coding. 
The END statement terminates the complle phase.

ELLEN: Now I will put an END statement at the end of the program. See whether this eliminates the error, Eugene.

EUGENE: Right In order to save myself the trouble of typing in the rest of the programs that we will be using in this lesson, I have already put the programs into the computer. All I need to do is to push the "go" button.

[Computer output:

$w=75.5$

$S=180.0$

Fow $W$

END

\section{BXECUTION}

**ERROR**STOP STATEMENT MISSING** ]

This time the complle phase was accomplished without error, and the execution phase was begun. But this time an error occurred during the execution. Notice that the first error was a comptle error since it occurred during comptiling. This error is an execution error since it occurred during the execution of the program. The problem this time is that I falled to tell the computer when to stop executing the program; I gave it no instruction to make it stop, so the computer tells me about it with this diagnostic message.

Remember that the computer can do only what we tell it to do; we must tell it to stop the execution of the program when we want it to stop. We do this with the sTOP statement.

SEYMOUR: The STOP statement stops the execution of the program. The STOP statement terminates the execute phase. STOP THE EXECUTION!

/Visual Man being executed on the gallows and someone yeling, "Stop the executionl" 
ELLEN: We need to put the STOP instruction Into the program. Where must we put it? First, let's raise the question, does the STOP statement have to be compiled? The answer, of course, is yes. It must be complled. So it must be placed before the END statement, mstn't 1t? (The END statement must always be last, anyway.) Now, where in the program do we want the computer to stop? Logically we want it to stop when it is finlshed with the adding of $W$ and $S$ together. So I will put the STOP Instruction here.

[Places on board:

$$
\begin{aligned}
& W=75.5 \\
& S=180.0 \\
& F-W+S \\
& S T O P \\
& \text { END }
\end{aligned}
$$

Does that eliminate the execution error, Eugene?

EUGENE: We'11 see. I've already put this new program into the computer. [Computer output:

$$
\begin{aligned}
& W=75.5 \\
& S=180.0 \\
& F=W+S \\
& S T O P \\
& \text { END }
\end{aligned}
$$

\section{EXECUTION}

EXECUTION COMPLETED ]

This time the compile phase was done without any errors, and the execute phase was also completed. But where do you suppose the answer is? Remember that the computer can do only what we tell it to do. Did we tell it to write out the answer for us? No, we didn't. So the answer is still inside the computer's memory. How do we get the answer out? Ellen will show you. ELLEN: We want the answer, F, the frontage, to be written out after 
It is calculated and before the computer stops execution. Clearly, the WRITE instruction tells the computer to write out the value of $F$, which is the answer we want. The FORMAT statement is required; it tells the computer the form of the written output and we'll save it for later. But notice especially that the "l" preceding the FORMAT statement corresponds to this "l" in parentheses in the WRITE statement. [Program on board:

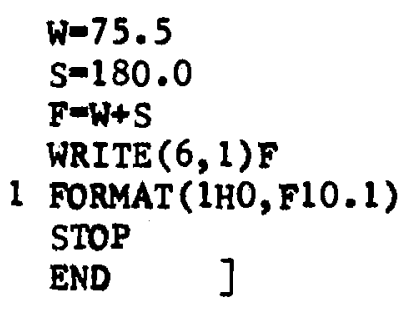

SEYMOUR: The WRITE statement: write parenthesis six comma one parenthesis F.

VIsUaI7 WRITE $(6,1)$ F

EUGENE: Now I'll show you what this new program does.

[Computer output: $\quad$ We75.5

$S=180.0$

F $-W+S$

WRITE $(6,1) F$

1 FORMAT (1HO, F10.1)

STOP

END

EXECUTION

255.5

EXECUTION COMPLETED ]

At last, the program does exactly what we wanted; and you see why we have to have all of these statements in order to have a complete program.

Now let's consider the order in which the FORTRAN statements 
in the program were executed.

ELLEN: I was very careful to put the statements in the order that they are in. It's very important to realize that the computer executed these statements from top to bottom. Let's see what happens when the order of the statements is changed. I will interchange the second and third statements. [Program on board: $\quad \omega=75.5$ $\mathrm{F}=\mathrm{W}+\mathrm{S}$ $S=180.0$ WRITE $(6,1) F$

1 FORMAT (1HO, F10.1) STOP END

Notice that we are now telling the computer to add the number represented by "W" to the number represented by " $S$," but only the value of $W$ is known at that point in the program. Show us what the computer does now, Eugene.

EUGENE; OK.

[Computer output:

$W=75.5$

$\mathrm{F}=\mathrm{W}+\mathrm{S}$ $S=180.0$ WRITE $(6,1) F$

1 FORMAT (1HO,F10.1) STOP

END

EXECUTION

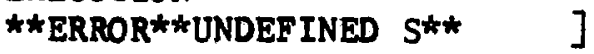

The computer was unable to add the numbers since it didn't know what one of them was, specifically S.

Let me illustrate the difficulty so that you won't forget it with a nursery rhyme. I'll admit that the example is a bit bizarre, but I want you to remember it.

You all know about Mother Hubbard. 
/V1sual "Mother Hubbard" sequence of frames

She went to the cupboard to get her poor dog a bone, but the cupboard was bare and the poor dog had none. Now I'll expand the story a little and put a happier ending on $1 t$.

/Visual7 Second "Mother Hubbard" sequence

Mother Hubbard, finding no food for her poor dog in the cupboard, goes to the bank to get some money out of her account so that she can go to the store and get her dog some food.

This sequence of events has a logical order. Now if we change the order of events, then the sequence becomes incorrect. For example, when Mother Hubbard finds her cupboard empty, sup-

Visuall Third "Mother Hubbard" sequence

pose that she goes to the store without any money, not having gone to the bank, and tries to buy the dog food. Well, that's what happens; she's klcked out of the storel The poor dog still doesn't get any food.

/Visual Unhappy dog from first sequence

Yet, that's just exact ly what some FORTRAN programmers try to do sometimes when they get their FORTRAN statements out of the proper order. They try to feed the dog with no food. Isn't that right, Ellen?

ELLEN: It certainly is I In fact, that's just what we did when we changed the order of the program. Th1s program tells the computer to find the sum of $W$ and $S$, but the computer doesn't know 
what $S$ is since $S$ is not defined unt1l the next statement. The order of execution of a FORTRAN program is from top to bottom as we would expect. And if we get the statements out of order, then In effect we may be trying to feed the dog without food, which is nonsense. Just as Mother Hubbard got kicked out of the store, we get kicked off the computer. We usually call that being "bombed off" the computer.

VIsuall Bomb blast

So, let's put the statements of the program back into the proper order. [Does so on board.]

There's one statement, however, that we don't have to be concerned about. The FORMAT statement here is what is called a nonexecutable statement; it is not an instruction that the computer can perform as it can STOP or WRITE or add $W$ and $S$, which are all executable statements. The FORMAT statement is just a blueprint or a pattern of how we want the printed output to look. Since the FORMAT statement is nonexecutable, we can put it anywhere in the program - as long as it goes before the END statement, of course. [Places FORMAT first in program.] since the "l" In front of the FORMAT statement corresponds to the "l" in the WRITE statement, as long as the WRITE statement is in the proper order, the FORMAT statement referred to by the WRITE statement will be properly used, regardless of its position in the program.

EUGENE: [Now sitting in number 1 position.] In this particular program, the only arithmetic operation that we used was addition. 
We can, of course, also use other operations on the computer. The four basic arithmetic operations are addition, subtraction, multiplication, and division. The DORTRAN symbols for addition and subtraction are just what we would expect them to be.

VIsual Illustrating addition symbol (t)

We use the plus sign for addition.

V1suall Illustrating subt raction symbol $(-)$

We use the minus sign for subtraction.

The symbols for multiplication and division, however, are somewhat different from what we might expect.

VIsual Illustrating multiplication symbol (*)

We use the asterisk, or star as we commonly say, for multiplication.

VIsual Illustrating division symbol $(/)$

We use the virgule, or more commonly, the slash, for division. [Camera to Eugene.] We may also use parentheses in FORTRAN just as we do in algebra. For example, if we wanted to find the distance around the property, we could write $P=2.0 *(w+S)$, is.

V1sual $P=2.0 *(W+S)$

where I have used "p" for the perimeter, the distance around the property.

[Camera on Eugene.] Now, with Ellen's assistance, I'll show 
you another very useful feature of FORTRAN.

ELLEN: In our program we have used simply "W" for the west side and "S" for the south side. We could just as well have called the west side "WEST" and the south side "SOUTH."

[Places on board: WEST $\mathbf{- 7 5 . 5}$

SOUTH $=180.0$

FRONT-WEST+SOUTH

WRITE $(6,1)$ FRONT ]

The only requirements in the names that we choose are that they begin with letters of the alphabet and that they do not contain more than six characters.

We could also have used numbers in the names. For example, I could have called the west side "SIDEl" and the south side "SIDE2." [Places mag cards to the side of the programa] Notice again that these names begin with leters of the alphabet and are not more than six characters long.

EUGENE: We are relatively unlimited in our cholce of names in FORTRAN. Usually we choose names that are descriptive of the problem, as we did with WEST for the west side and SOUTH for the south side, for example. There is one restriction, however; for the present we should restrict the names to names beginning with the letters $A$ through $H$ and 0 through $Z$.

Visual Animation with man pointing to $A=H$ and $0-Z$

The letters I through $N$ are reserved for a special purpose.

I have been using the typewriter terminal for demonstrating the use of the computer. Ordinaxily when one uses the computer for FORTRAN problems, he puts his program on punched cards and uses these cards for input to the computer. Since you will be 
using punched cards for your programs, I want to show you how to go about the task of putting your program on punched cards and running the program on the computer. Here is an example of a computer card printed especially for use in FORTRAN.

V1suall FoRTRAN Statement Card (s11de)

Let's take a closer look.

Tisual7 Camera card with FORTRAN Statement Card, Carl pointing

You will notice that the card contains 80 columns. These 80 columns are marked off in blocks. Colums 1-5 are used for statement numbers, such as the "1" in front of the Format stateV1sual Super: 1 FORMAT (1H0,F10.1)

ment that we used. Column 6 has a special use that we' 11 discuss when we need to make use of 1t. Columns 7-72 are the columns in which we put anything that we wish the compiler to translate; in other words, we put the FORTRAN statements anywhere in these columns. For example, we would put the FORTRAN statement

VIsual Super: WEST -75.5

WBST $=75.5$ or the statement that stops the execution

VIsual Super: STOP

anywhere in colums 7-72. Finally, in columns $73-80$, the last elght columns, we can put anything we wish, such as the programmer's name or initials or any other information for identifica- 
tion purposes. These last elght columns are not complled. Let me remind you that the FORTRAN statement card has the columns marked off and labeled, so you can't go wrong if you pay attention to the labels and the lines on the card.

There is an additional label in column 1 of the card. The label says "C for comment." Frequently the programmer needs to write certain information into the program that is not for the computer, but for the programmer himself or for the purpose of Identification of the program. Since these are comments for the programmer and are not to be complled, we must code such comments by punching a " $C$ " in column 1 of the card on which this information appears. Then the compiler will not complle that statement. We may use any columns for comments as long as a "C" appears in column 1 .

[Camera to Eugene.] I have punched the program that is on the board Into computer cards.

VIsual Punched deck fanned out

Notice that the information punched on the card is also printed at the top of the card so that we can read 1t. I have placed a comment card at the front of the program for identifying $1 t$. Notice the " $C$ " punched in column 1. There is a single card for each statement, and the cards are placed so that the first statement, WEST-75.5, is the first card; and END, the last statement, 1s the last card. The cards are read from front to back. [Camera to Eugene.] How do you punch the cards? Movie Keypunch, card reader, line printer sequence 
Here is a person using a card punch or keypunch machine. The keyboard is very similar to a typewriter keyboard. There you see a card that has been punched passing through the card track. Once you get your program punched properly, then you place your deck of cards, along with the control cards for the particular computer system, on the card reader. This card reader you see here reads cards at the rate of up to 1000 cards per minute.

After the program has been complled and executed, the output comes out on the high-speed line printer. This line printer is capable of printing 1100 lines per minute. It's a fantastic machine in its own right!

The keypunch machine, card reader, and line printer serve the same purpose that our typewriter terminal here does. Since these machines are not portable, we cannot bring them into the studio, so we substitute for these machines the portable typewriter terminal.

SEYMOUR: Write parenthesis six comma one parenthesis FRONT.

\section{VISUaI WRITE $(6,1)$ FRONT}

EUGENE: That, incidently, was seymour, who will be helping me out along. He's a fine volce, that seymour!

SEYMOUR: Thank you !

EUGENE: And courteous too! Isn't he marvelous? Now you know enough to write a simple FORTRAN program. Try it $!$

V1sual Caboose with END on it 


\section{APPENDIX C \\ QUESTIONNAIRE GIVEN AT THE BEGINNING \\ OF THE SEMESTER}

In order to obtain an attitude score from this questionnalre, questions 14, 17, and 20 were scored from 1 (most unfavorable response to ITV) to 5 (most favorable response to ITV). The response "undecided" was given a value of 3 , the same as a response of "don't care" or "neither favorable nor unfavorable." The sum of the values given to the questions is the score. 
Name

Sex

Age

Classification

College

Major

1. In what city and state (c1t1es and states) did you attend elementary school?

City

State

City State

2. What was the approxiante size of the elementary school(s) you attended?
a. Less than 250
b. $250-500$
c. $500-750$
d. $750-1000$
e. More than 1000 .
f. Don't know

(If you attended more than one school, Indicate the city by the size you marked.)

3. Did you ever have a subject in elementary school in which television instruction was used In any way?

a. No (Go directly to question 6, page 2.)

b. Yes (Please oupply the information for question 4.)

4. In what subject or subjects was Instructional television used, and approximately how many times per week was it used? (Mark also the column headed "Total" If the entire course was taught by television.)

\begin{tabular}{c|c|c|c|c|c|c|c|c|c} 
Subject & $\begin{array}{c}\text { Less } \\
\text { than 1 }\end{array}$ & 1 & 2 & 3 & 4 & $\begin{array}{c}5 \text { or } \\
\text { more }\end{array}$ & $\begin{array}{c}\text { Don't } \\
\text { know }\end{array}$ & Total & C1ty \\
\hline & & & & & & & & & \\
\hline & & & & & & & & & \\
\hline & & & & & & & & & \\
\hline
\end{tabular}

5. How would you rate your overall attitude toward instructional television at the time?
a. Very favorable
b. Favorable
c. Netther favorable nor unfavorable
d. Unfavorable
e. Very unfavorable
f. Undecided 


\section{Page 2}

6. In what city and state (citles and states) did you attend secondary school?

C1ty State

Ctty State

7. What was the approxinate size of the secondary school(s) you attended?
a. Lese than 250
b. $250-500$
c. $500-750$
d. $750-1000$
o. Nore than 1000
f. Don't know

(If you attended more than one school, indicate the city by the size you marked.)

8. Did you ever have a subject In secondary school in which Instructional television was used In any way?

a. No (Go directly to question 11, page 3.)

b. Yes (Please supply the Information for question 9.)

9. In what subject or subjects was instructional television used, and approximately how many times per week was it used? (Mark also the column headed "Total" if the entire course was taught by television.)

\begin{tabular}{|c|c|c|c|c|c|c|c|c|c|}
\hline Subject & $\begin{array}{c}\text { Less } \\
\operatorname{than} 1\end{array}$ & 1 & 2 & 3 & 4 & $\left|\begin{array}{ll}5 & \text { or } \\
\text { more }\end{array}\right|$ & $\begin{array}{l}\text { Don't } \\
\text { know }\end{array}$ & Total & City \\
\hline & & & & & & & & & \\
\hline & & & & & & & & & \\
\hline & & & & & & & & & \\
\hline & & & & & & & & & \\
\hline
\end{tabular}

10. How would you rate your overall attitude toward instructional television at the time?
a. Very, favorable
b. Favorable
c. Ne1ther favorable nor unfavorable
d. Unfavorable
e. Very unfavorable
f. Undecided 
Page 3

11. Bave you ettended any other colleges or univeralties other than Oklahoma State Univere1ty?

a. No (Co directly to question 12.)

b. Ies (Plesese eupply the Inforation for the table below.)

\begin{tabular}{l|l|l|l} 
College & CIty & state & $\begin{array}{l}\text { Approxinate } \\
\text { enrollont }\end{array}$ \\
\hline & & & \\
\hline & & & \\
\hline
\end{tabular}

12. Heve you ever taken a course in college in which instructional televiaion was used In any way?

a. No (Go directly to question 14.)

b. Yes (Plesse supply the Information for question 13.)

13. In what courses was instructional television used, and approxinately how many times per week was it used? (Mark also the colum headed "Total" if the entire courae was taught by television.)

\begin{tabular}{l|l|l|l|l|l|l|l|l|l} 
Course & $\begin{array}{c}\text { Lese } \\
\text { than 1 }\end{array}$ & 1 & 2 & 3 & 4 & $\begin{array}{l}5 \text { or } \\
\text { more }\end{array}$ & $\begin{array}{l}\text { Don't } \\
\text { know }\end{array}$ & Tota1 & College \\
\hline & & & & & & & & & \\
\hline & & & & & & & & & \\
\hline & & & & & & & & & \\
\hline
\end{tabular}

14. How would you rate your overall attitude toward instructional televialon at the college level, regardless of whether you huve been exposed to it?

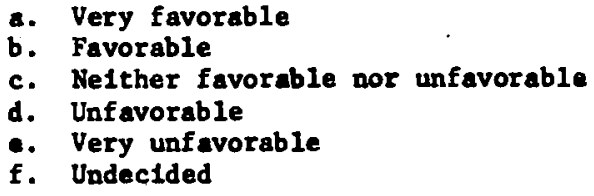

15. Have you ever watched programs of an Instructional nature on public televiaion (National Educational Television, Public Broadcasting Corporation, Oklahoma Bducational Television Authority, etc.) outside a etructurad classroom setting?
a. No
b. Yes
c. Don't know 
Page 4

16. Dow would you rate your overall attitude toward public televielon, regardlees of Whather you have viawed it?
a. Very favorable
b. Favorable
c. Welther favorable nor unfavorable
d. Unfavorable
a. Very unfavorable
f. Undecided

17. What 1s your reaction to the fact that inctructional television is used in this course?
a. Very favorable
b. Favorable
c. Nelther favorable nor unfavorable
d. Unfavorable
a. Very unfavorable
f. Undec1ded

18. What do you expect that your attitude toward the we of Instructional televiaion In thle course will be at the conclusion of the coureet
a. Very favorable
b. Favorable
c. Walther favorable nor unfavorable
d. Unfavorable
e. Very unfavorable
f. Undec1ded

19. How would you rate your overall attitude toward the conventional cleseroom lecture?
a. Very favorable
b. Favorable
c. Ne1ther favorable nor unfavorable
d. Unfavorable
c. Very unfavorable
f. Undecided:

20. Would you prefer that this course be taught ualng the conventional claseroon lecture or televiolon Instruction?
a. Strongly prefer conventional lecture
b. Lean toward conventional lecture
c. Don't care
d. Lean toward TV
e. Strongly prefer TV
f. Undecided 


\section{APPEIDIX D \\ QUESTTONALRE GIVEN AT THE MND \\ OF THE SEMESTER}

The attitude score based upon this questionnalre was obtained by scoring the responses from 1 (most unfavorable response to ITV) to 5 (most favorable response to ITV), using questions 1, 2, and 3 , and then accumulating the sum of the numbers. The response "undecided" was given a value of 3 , the same as a response of "don't care" or "nelther favorable nor unfavorable." 
Name

Lab section

Here is a record of your attendance for the semester.

Attended the conventional class times
Attended the IV class thes
Percent attendance to the TV class is

Please list one or more reasons in decreasing order of importance why you chose to attend or not to attend the IV class as you did; then please go to the next page. 
Thank you for your cooperation in participating in the experimental lecture sections. Please do this one last questionnaire. Your response will in no way effect your grade in the course.

1. How would you rate your overall attitude toward instructional television at the college level?
a. Very favorable
b. Favorable
c. Nelther favorable nor unfavorable
d. Unfavorable
e. Very unfavorable
f. Undecided

2. What is your reaction to the use of instructional television in this particular course?
a. Very favorable
b. Favorable
c. Nelther favorable nor unfavorable
d. Unfavorable
e. Very unfavorable
f. Undecided

3. Would you prefer that this course be taught using the conventional classroom lecture or television instruction?
a. Strongly prefer conventional lecture
b. Lean toward conventional lecture
c. Don't care
d. Lean toward TV
e. Strongly prefer TV
f. Undecided

4. Is your attitude toward instructional television different now from your attitude when you came into this course as a result of having seen at least one television lesson?
a. Attitude 18 unchanged
b. Att1tude toward TV 1 s improved
c. Attitude toward TV is worse than before
d. Undecided

5. Is your attitude toward instructional television at the conclusion of this course what you expected it to be when the course began?
a. Attitude is the same as expected
b. Attitude is better than expected
c. Attitude is worse than expected
d. Undecided 
APPENDIX E

THE SCHULZE SHORT DOGMATISM SCALE

The score on the dogmatism scale was obtained by adding 4 to each response and then accumulating the sum. If no response was marked, then zero was assigned before calculating the score. The higher the score 1s, the more dogmatic the respondent is. The total possible score is 70 . 
The following is a study of what the general public thinks and feels about a number of important social and personal questions. The best answer to each statement below is your personal opinion. We have tried to cover many different and opposing points of view; you may find yourself agreeing strongly with some of the statements, disagreeing just as strongly with others, and perhaps uncertain about others; whether you agree or disagree with any statement, you can be sure that many people feel the same as you do.

Mark each statemient in the left margin according to how much you agree or disagree with 1t. Please mark every one.

Write $+1,+2,+3$, or $-1,-2,-3$, depending on how you feel in each case.

+1: I agree a little

+2: I agree on the whole

+3: I agree very much
-1: I disagree a little

-2: I disagree on the whole

-3: I disagree very much

1. Most people just don't know what's good for them.

2. A person who thinks primarily of his own happiness is beneath contempt.

3. In the htstory of mankind there have probably been fust a handful of really great thinkers. ....

4. The worst crime a person can commit is to attack publically the people who believe in the same thing he does.

5. In the long run the best way to live is to pick friends and assoclates whose tastes and bellefs are the same as one's own.

6. In this complicated world of ours the only way we can know what is going on is to rely upon leaders or experts who can be trusted.

7. Fundamentally, the world we live in is a pretty lovely place.

8. While I don't like to admit this even to myself, I sometimes have the ambition to become a great man like Elnstein, or Beethoven, or Shakespeare.

9. Once I get wound up in a heated discussion I just can't stop.

10. It is often desirable to reserve judgment about what's going on until one has a chance to hear the opintons of those one respects. 


\section{NPENDIX E}

\section{ATTENDANCE RECORDS FOR ALL STUDENTS BY LESSONS}

Table XIX contains the attendance data for the students enrolled In the experimental section.

The column labeled "Ip" contains the student's Identification number. The first two digits of the number are the laboratory section number in which the student was enrolled, and the last four digits form a number used for alphabetical sequencing.

The column labeled "CODE" contains the notation used by the University for Identifying the student's college, his classification, and his sex. The abbreviations used for colleges are as follows:

$\begin{array}{ll}\text { AG } & \text { Agriculture } \\ \text { AS } & \text { Arts and Sciences } \\ \text { BU } & \text { Business } \\ \text { BD } & \text { Bducation } \\ \text { EN } & \text { Engineering } \\ \text { GR } & \text { Graduate } \\ \text { HE } & \text { Home Economics } \\ \text { TI } & \text { Technical Institute }\end{array}$

The number in the code indicates the classification of the student as follows:

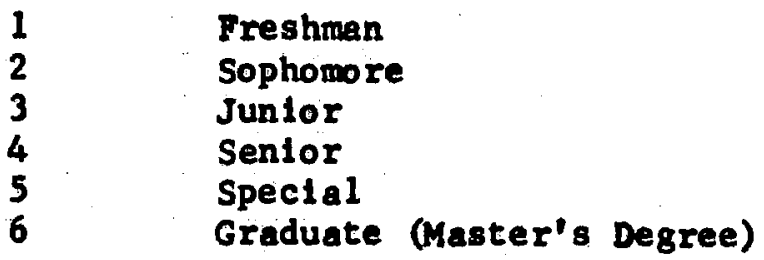

The sex of the student is indicated by "M" for male and "F" for female. 
For example, a code of "BUlF" means a female freshman enrolled in the College of Business.

The code of "AUD" means that the student was auditing the course.

All students were required to attend the first TV lesson on 25

January. The students were free to choose whether they attended the

TV class or the conventional class (designated "LIVE" in the table) beginning with the second lesson on 1 February. 
TABLE $X I X$

ATTENDANCE RECOROS FOR ALL STUDENTS BY LESSONS

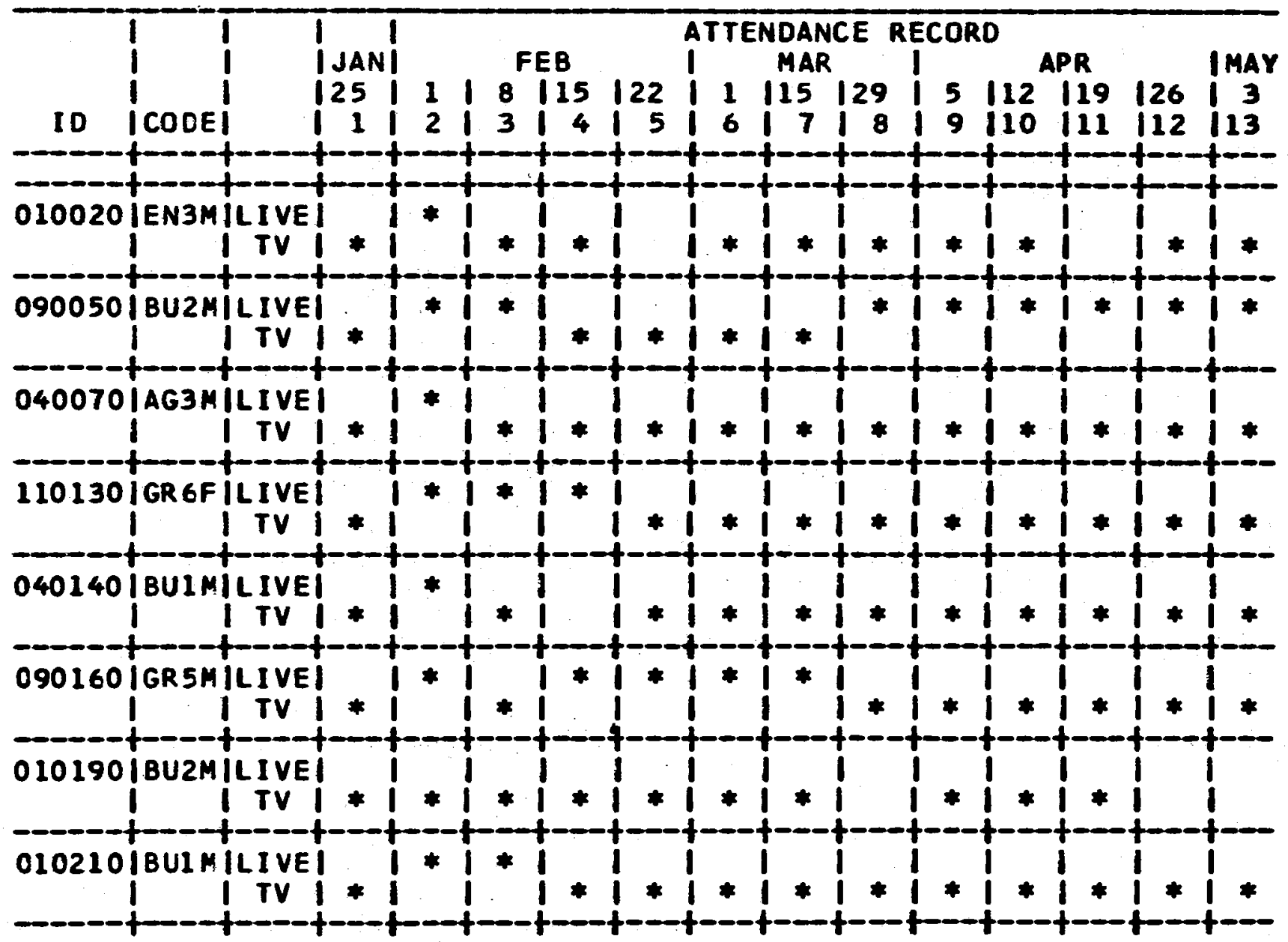




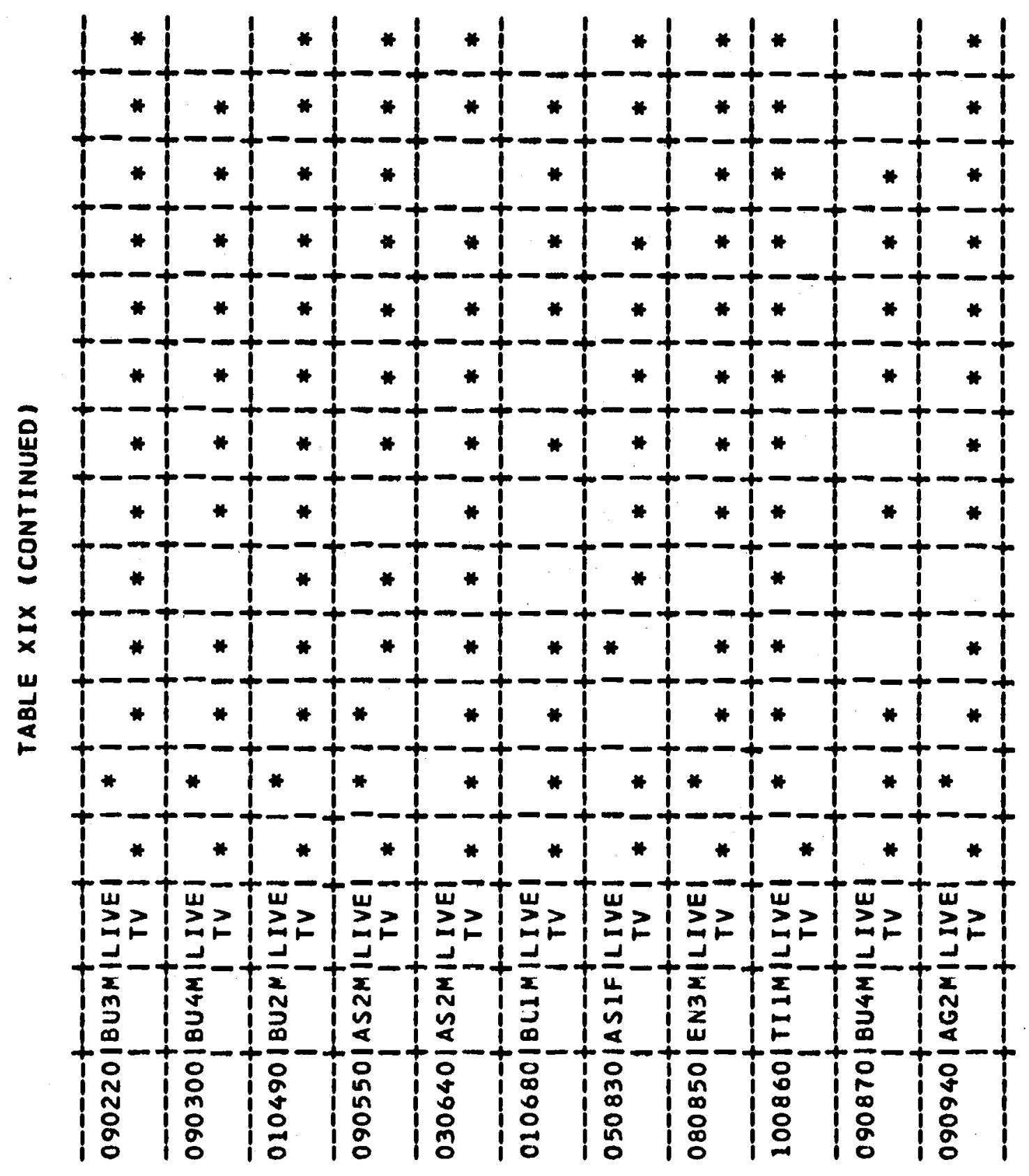


TABLE XIX (CONTINUED)

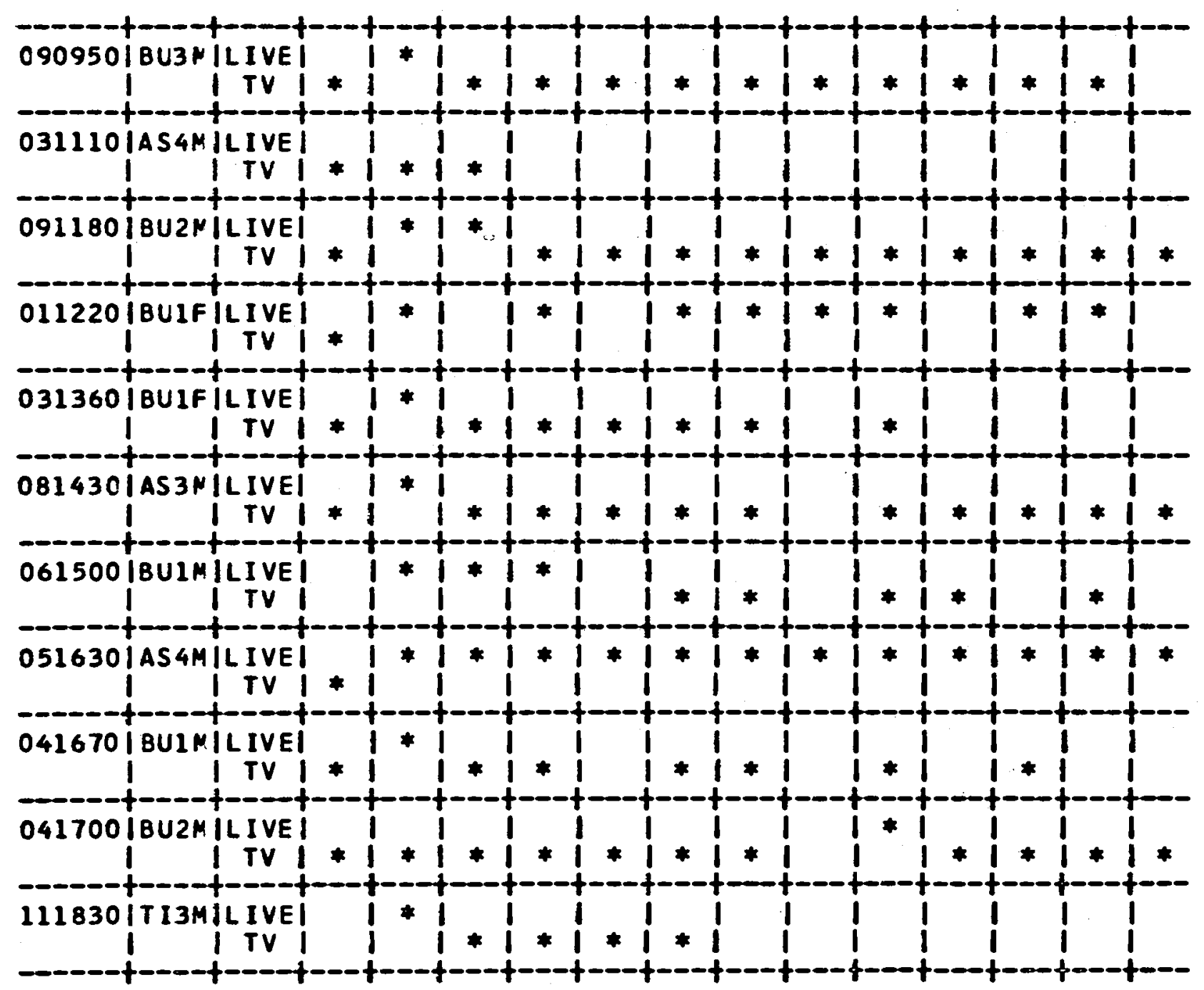




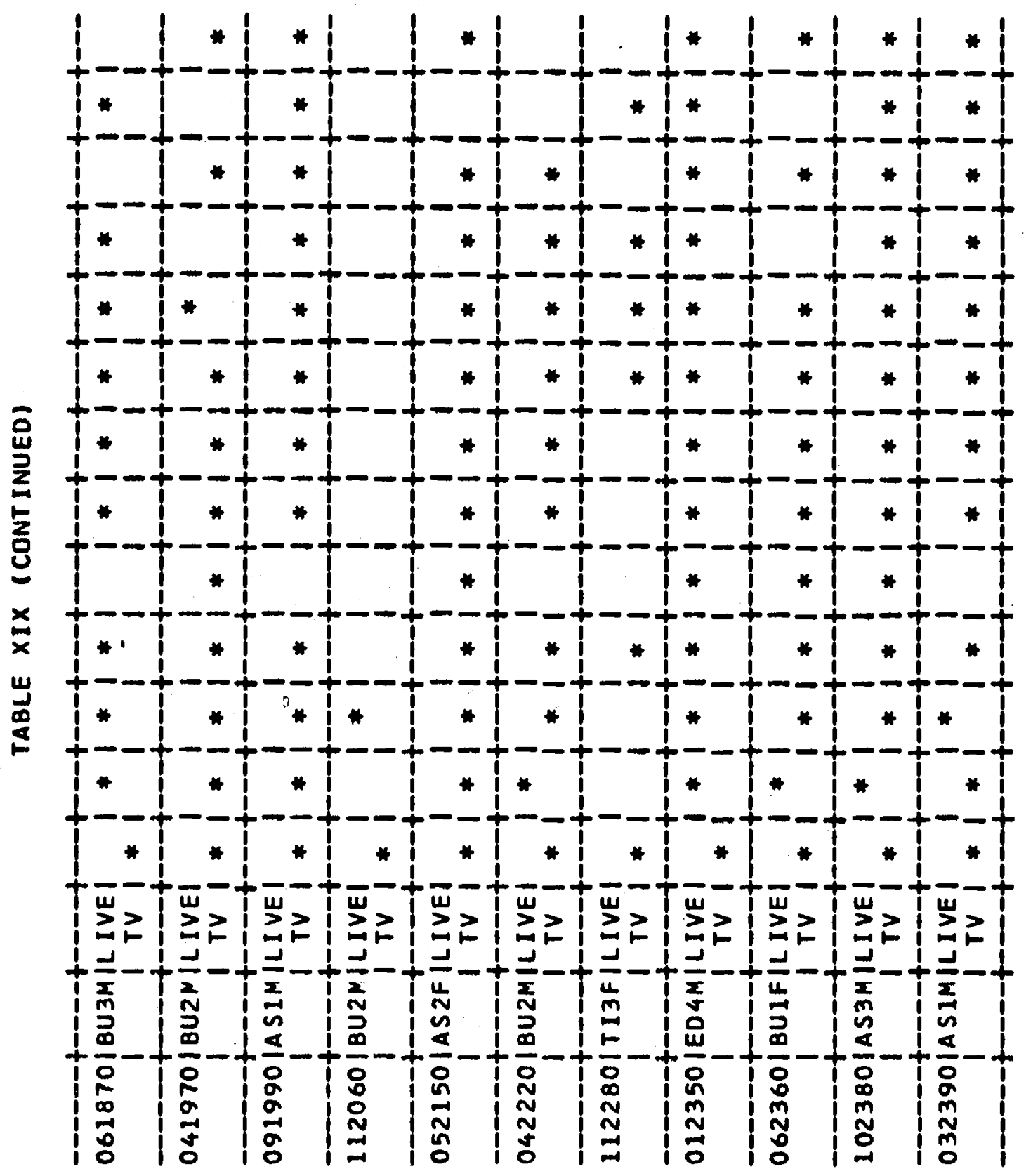




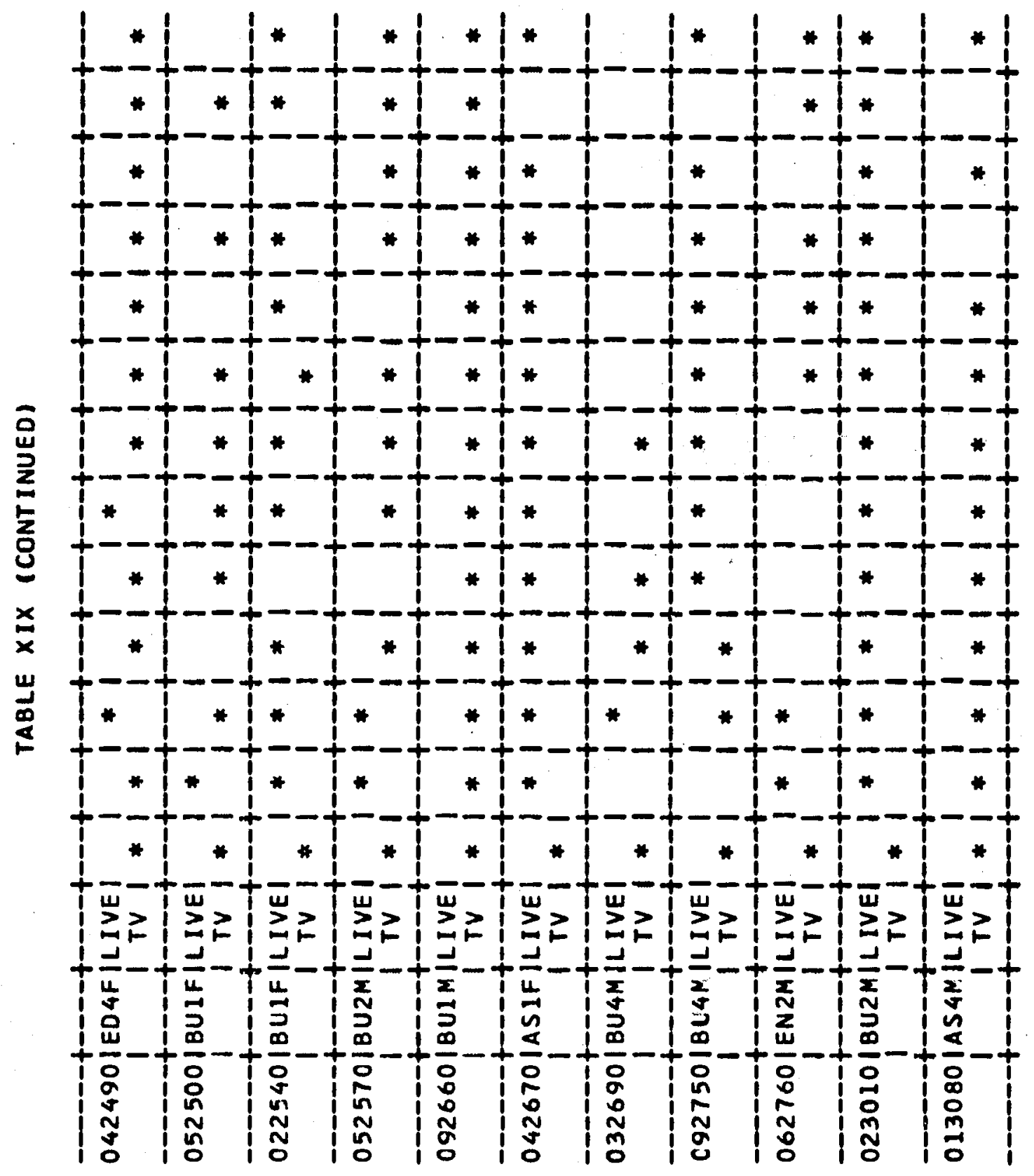


TABLE XIX (CONTINUED)

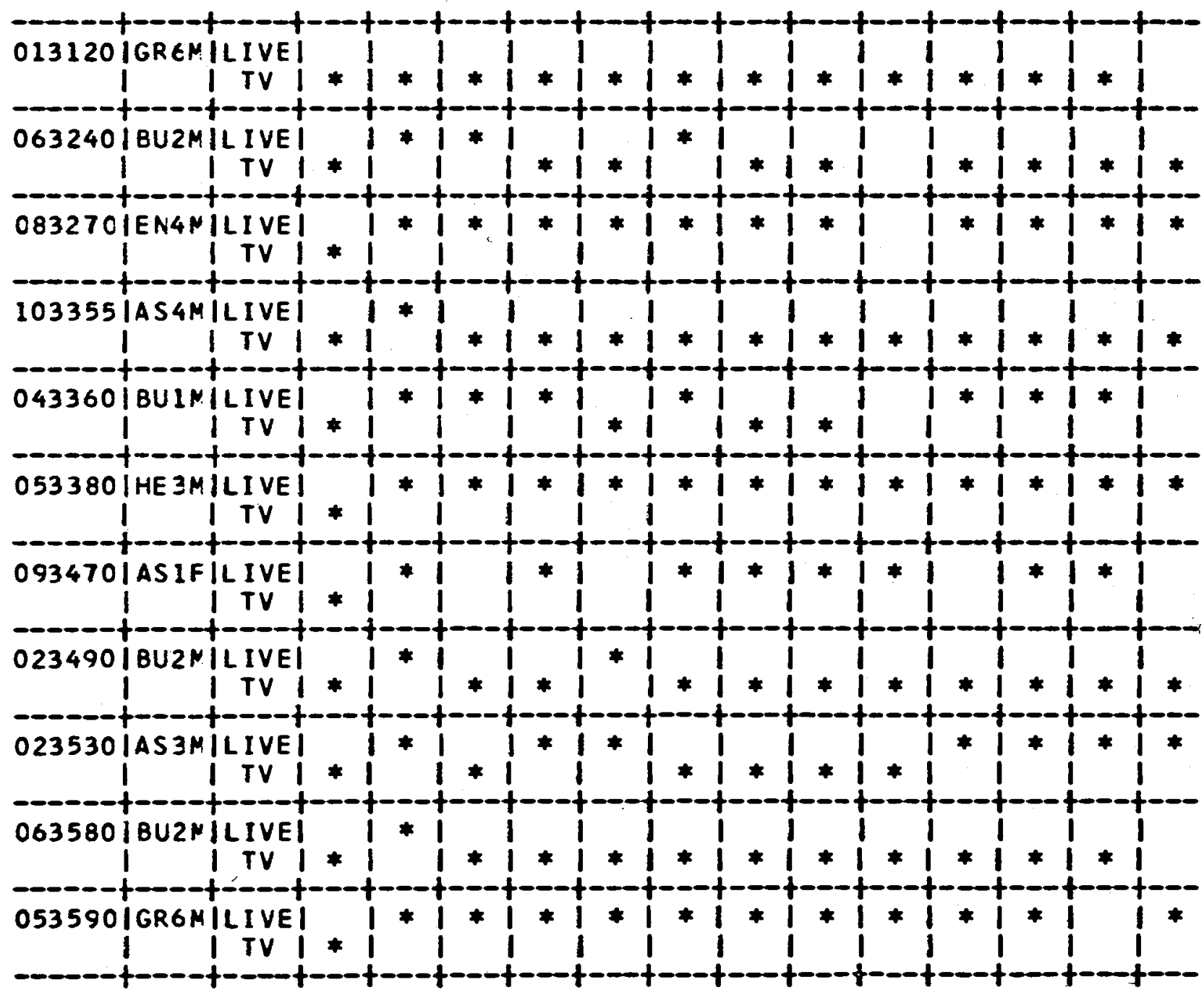




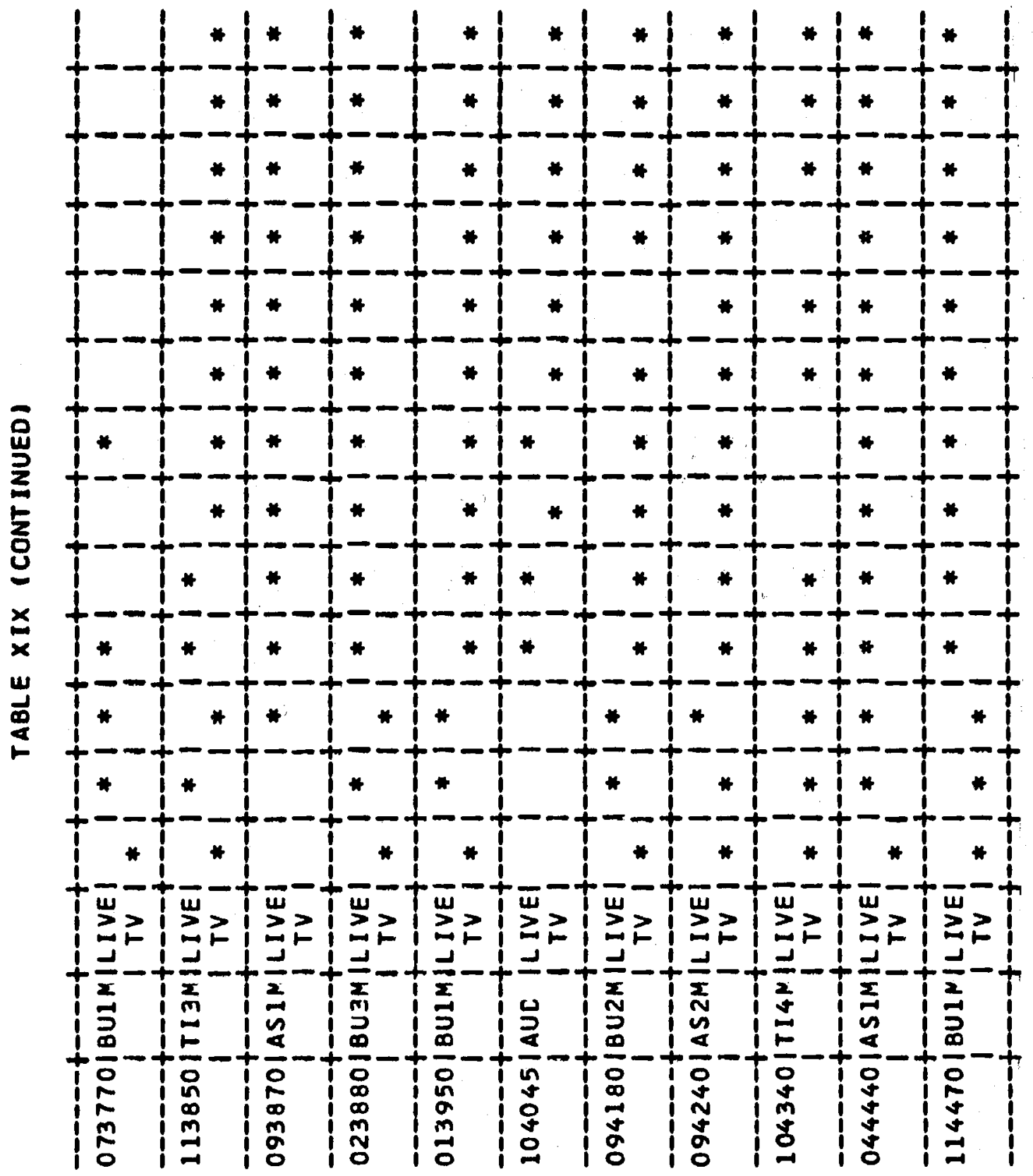


TABLE XIX (CONTINUED)

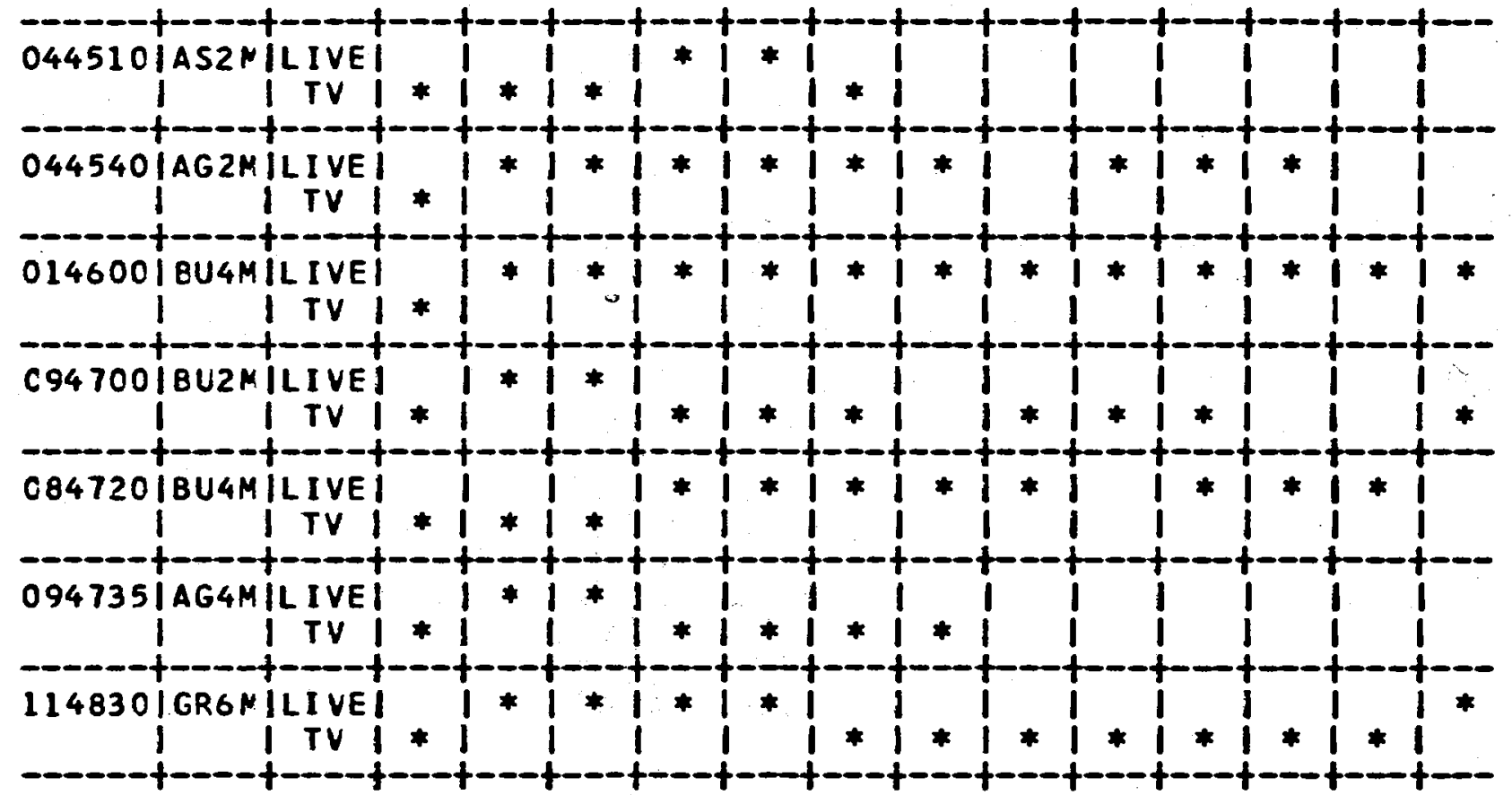




\section{APPENDIX G}

\section{SUMMARY OF ATTENDANCE DATA BY STUDENTS}

Table XX contains a summary of the attendance record for each student enrolled in the experimental section starting with the second lesson when the cholce of attending the TV class or the conventional class was avallable.

The "ID" and "CODE" columns are explained In Appendix F. The "\% TV ATTENDED" is based upon the number of times the student attended the TV class out of the total number of times he attended both classes.

The column labeled "TIMES CHANGED" shows the number of times the student changed from one class to the other after the second lesson. 
TABLE XX

SUMAARY OF ATTENDANCE DATA BY STUDENTS

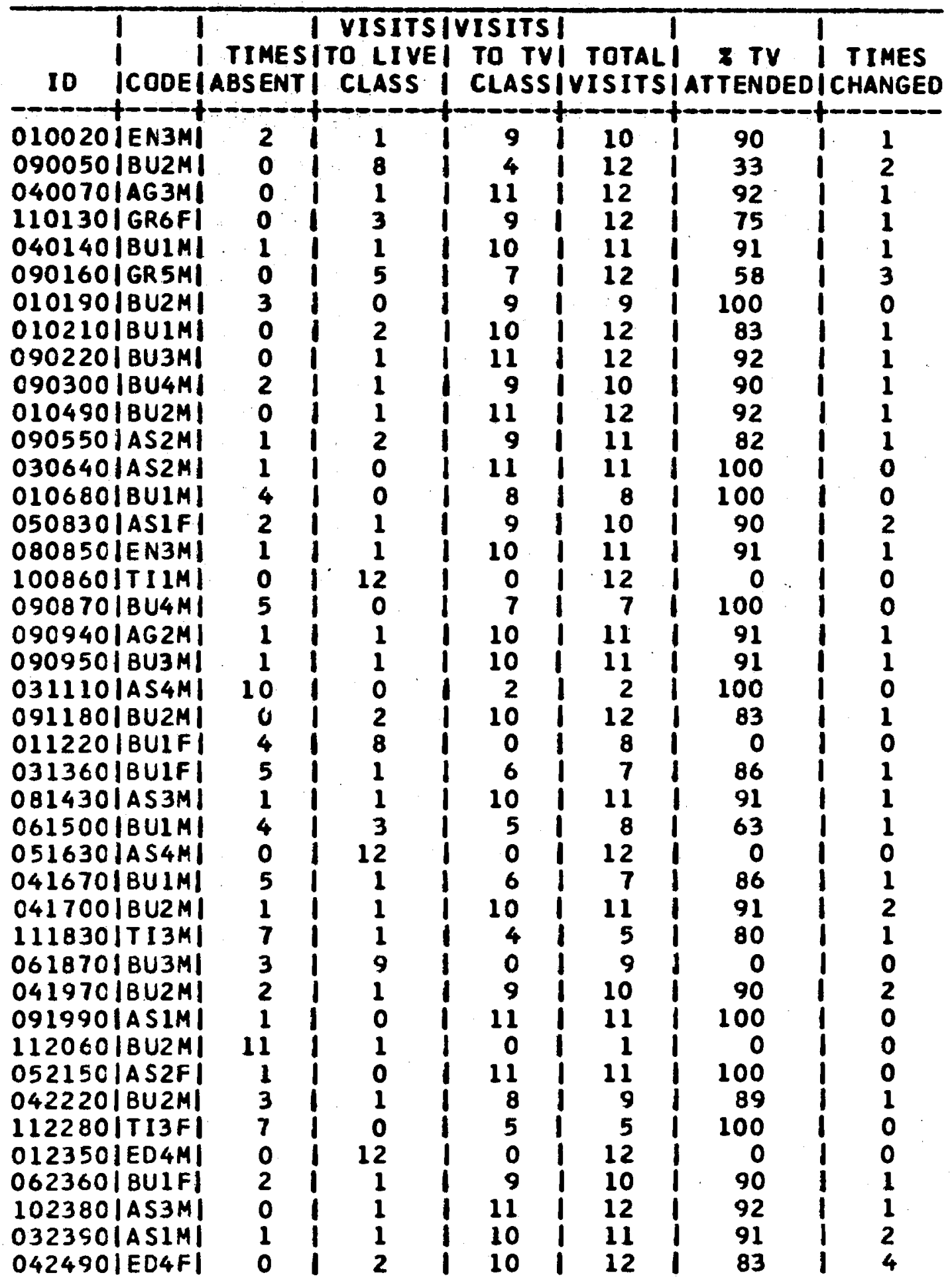


TABLE XX (CONTINUED)

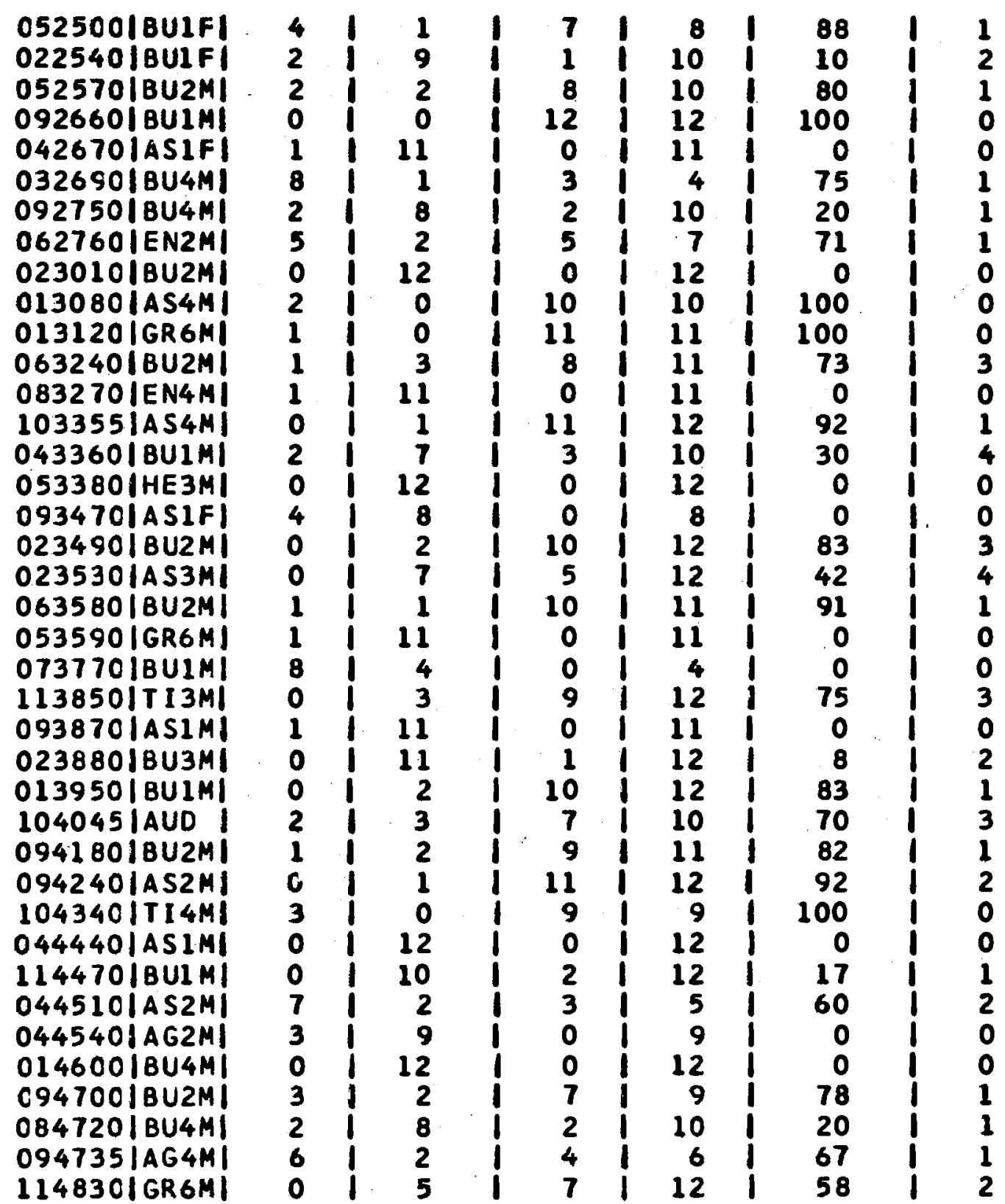




\section{APPENDIX H}

ATTITUDE SCORES, CUMULATIVE GRADE

POINT AVERAGES, AND PERFORMANCE

IN THE COURSE

Table XXI 1ists some miscellaneous data used in the statistical analysis of the attendance data.

The colurms labeled "ID" and "CODE" are explained In Appendix F. Prior exposure to instructional television is coded in the column labeled "PRIOR ITV"; a "l" indicates no prior exposure, and a "2" indicates prior exposure.

In order to obtain an attitude score on the pretest questionnalre (Appendix C), questions 14, 17, and 20 were scored from 1 (most unfavorable response to ITV) to 5 (most favorable response to IIV). The response "undecided" was given a value of 3 , the same as a response of "don't care" or "nelther favorable nor unfavorable." The sum of the values given to the questions was used as the score.

The attitude score on the posttest was obtalned by scoring questions 1, 2, and 3 of the posttest questionnatre (Appendix D) in the same manner as the pretest questionnaire was scored.

The score on the dogmatism scale (Appendix E) was obtalned by adding 4 to each of the responses and accumulating the sum of the numbers. If no responsd was marked, then a zero was assigned before calculating the score. More dogmatic respondents score higher. 
The grade point averages were obtained from the office of the Registrar and are cumulative grade point averages through the Fall Semester of 1970. (Grade point averages were not available for those students enrolling for the first time or enrolling after a break in enroliment.)

The score for the semester is based on a total of 102 points. 
TABLE XXI

ATTITUDES, CUAULATIVE GRADE POINT

AVERAGES, ANO COURSE PERFormanCE

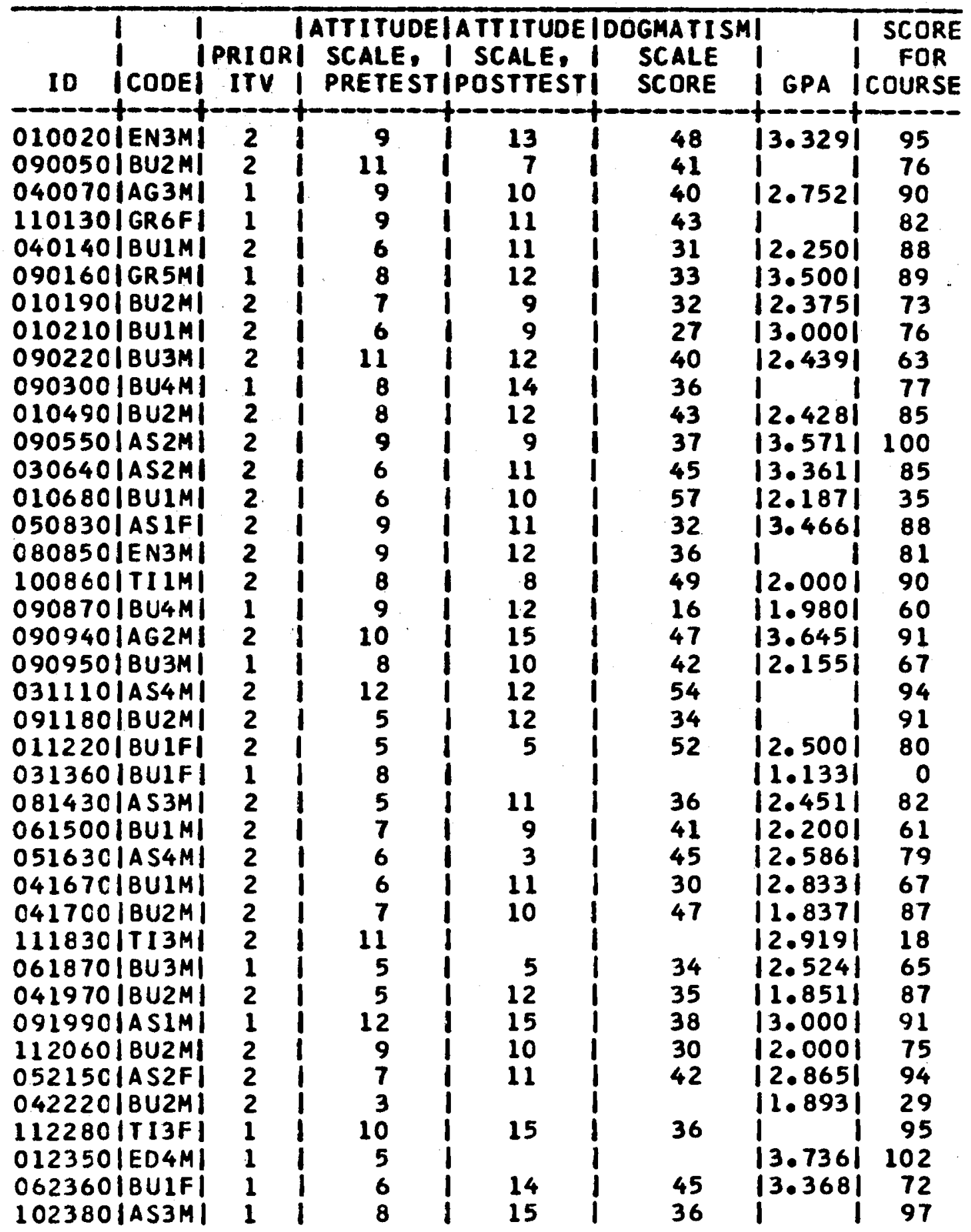


TABLE XXI (CONTINUED)

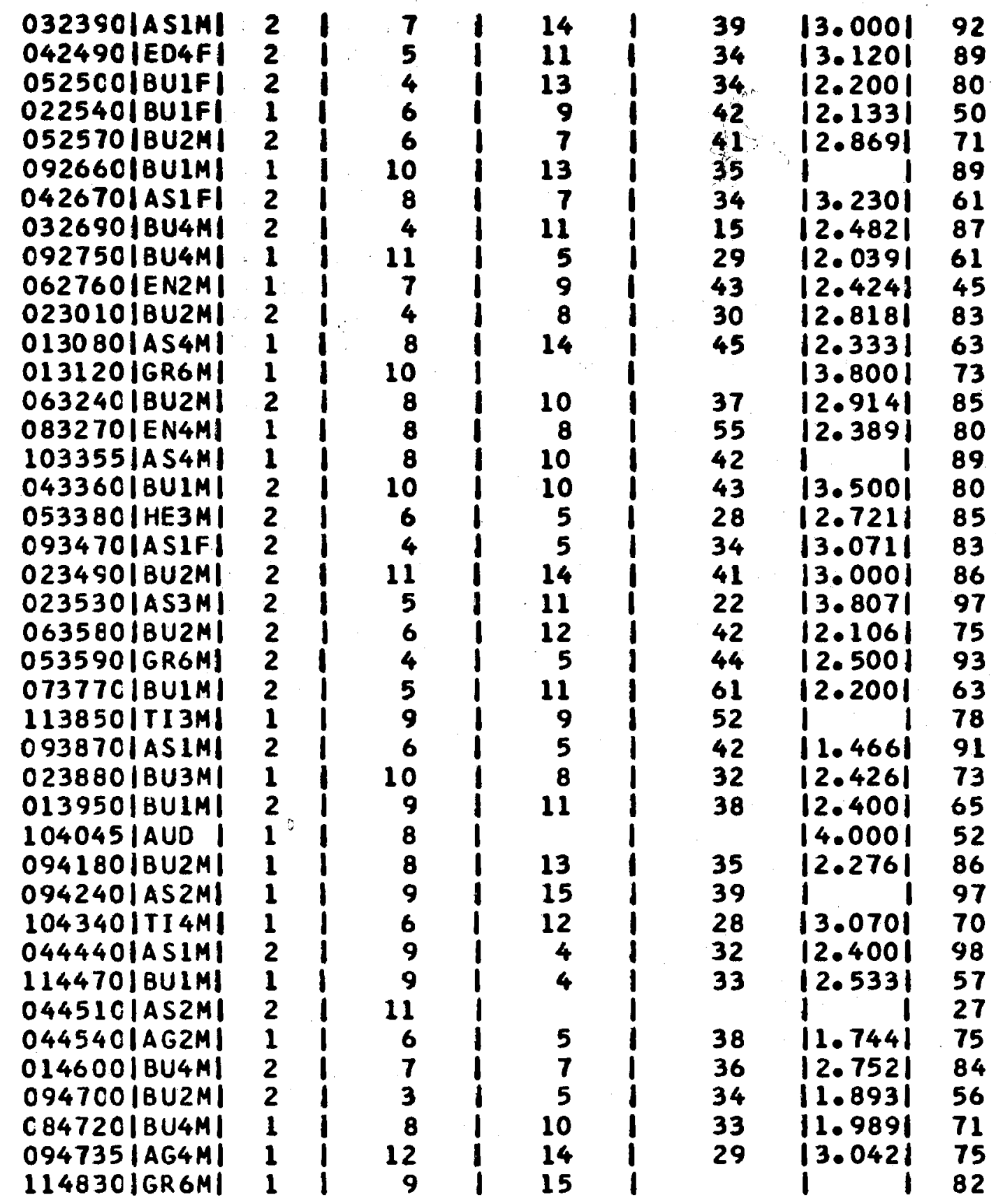




\author{
VITA 2 \\ Therold Eugene Batley \\ Candidate for the Degree of \\ Doctor of Education
}

Thesis: STUDENT ATTITUDES TOWARD A NEW APPLICATION OF INSTRUCTIONAL TELEVISION IN A COMPUTER PROGRAMMING COURSE

\title{
Major Field: Higher Education
}

Biographical:

Personal Data: Born in Memphis Tennessee, July 17, 1935, the son of Therold B, and Gladys L. Bailey.

Education: Graduated from Messick High School, Memphis, Tennessee, in 1953; received the Bachelor of Science degree from Harding College, Searcy, Arkansas, with majors in chemistry and mathematics, in 1957; received the Master of Science degree from Oklahoma State University, with a major in chemistry, in 1962; attended the University of Oklahoma during the sumers of 1962 and 1963; attended Central State College, Edmond, Oklahoma, in 1966; completed requirements for the Doctor of Education degree at Oklahoma State University in July, 1971.

Professional Experience: Mathematician Trainee, U. S. Army, Redstone Arsenal, Alabama, summers 1956-1958; Research Chemist, U. S. Army, Redstone Arsenal, Alabama, summers, 1964-1966; Instructor of chemistry and mathematics at Oklahoma ChristI an College, Oklahoma City, Oklahoma, 1961-1965; Assistant Professor at Oklahoma Christian College, 1965-1967; NDEA Fellow, Department of Chemistry, Oklahoma State University, 1967-1968; Graduate Teaching Assistant, Department of Chemistry, Oklahoma State University, 1958-1961; Graduate Teaching Assistant, Department of Computing and Information Sciences, Oklahoma State University, 1968-70; Graduate Associate (Instruction), Department of Computing and Information Sciences, Oklahoma State University, 1970-present; student member of Association of Computing Machinery. 